\title{
Textos castellanos cuatrocentistas sobre dos mujeres de la Antigüedad romana abocadas al suicidio: Lucrecia y Sofonisba*
}

\author{
Tomás GonZÁLEZ RoLÁN \\ Universidad Complutense de Madrid \\ grolan@ucm.es \\ Pilar SAQUero SuÁREZ-SOMONTE \\ Universidad Complutense de Madrid \\ psaquero@ucm.es
}

Para Charles Faulhaber, eximio romanista, con nuestra admiración y agradecimiento

Recibido: 20 de octubre de 2013

Aceptado: 8 de marzo de 2014

\section{RESUMEN}

Los autores, cuyos relatos sobre Lucrecia y Sofonisba gozaron de más predicamento entre los lectores y hombres de letras desde la Antigüedad al Renacimiento temprano, fueron Tito Livio, San Agustín, Petrarca y Coluccio Salutati. En este trabajo se analiza la presencia de dichos autores a través de las versiones castellanas realizadas en la primera mitad del siglo XV. Se ofrece una edición crítica de la traducción castellana de la Declamatio Lucretie de Salutati y la transcripción de una Carta secreta de Sofonisba a Masinisa, hasta el momento inédita.

Palabras clave: Suicidio. Lucrecia. Sofonisba. Textos castellanos. Tito Livio. San Agustín. Petrarca. Salutati. Alfonso de Madrigal.

GonzÁlez Rolán, T. - SAquero SúAReZ-Somonte, P., «Textos castellanos cuatrocentistas sobre dos mujeres de la Antigüedad romana abocadas al suicidio: Lucrecia y Sofonisba», Cuad. Fil. Clás. Estud. Lat. 34.1 (2014) 73-109.

\section{Castilian texts from $15^{\text {th }}$ century on two women from Roman antiquity doomed to suicide: Lucretia and Sofonisba}

\begin{abstract}
Livy, Saint Augustine, Petrarca and Coluccio Salutati were the authors whose Latin stories about Lucretia and Sofonisba succeed the most among readers and men of letters from Ancient times until early Renaissance. This work analyzes the presence of such autors through Castilian versions made in the

\footnotetext{
* Este trabajo se enmarca dentro del Proyecto de Investigación FFI2011-23805 financiado por el Ministerio de Ciencia e Innovación (ahora Ministerio de Economía y Competitividad).
} 
first half of the Fifteenth Century. It is also given a critical edition of the Declamatio Lucretie Castilian version, as well as the transcription of a secret Letter from Sofonisba to Masinisa, not yet published.

Keywords: Suicide. Lucretia. Sofonisba. Castilian versions. Tite Livy. Saint Augustine. Petrarca. Salutati. Alfonso de Madrigal.

González Rolán, T. - Saquero Súarez-Somonte, P., «Castilian texts from 15th century on two women from Roman antiquity doomed to suicide: Lucretia and Sofonisba», Cuad. Fil. Clás. Estud. Lat. 34.1 (2014) 73-109.

Sumario: 1. Introducción. 2. El suicidio de Lucrecia según Alfonso de Madrigal. 3. El relato de Tito Livio sobre la violación de Lucrecia. 4. La Declamatio Lucretie de Coluccio Salutati vertida al castellano. 5. La cartaginesa Sofonisba: su Epístola a Masinisa y el relato de Tito Livio. 5.1. Carta 'secreta' de Sofonisba a Masinisa 5.2. Versión de Tito Livio sobre el suicidio de Sofonisba. 6. Referencias bibliográficas.

\section{INTRODUCCIÓN}

Que el suicidio debió de ser una de las salidas no infrecuente para aquellas mujeres de la Antigüedad clásica, que por diversos motivos se sintieron desesperadas a causa de la perfidia, deslealtad, traición, olvido o pérdida de sus enamorados, nos lo muestran, por ejemplo, las Heroidas de Ovidio, libro en el que la mayor parte de sus heroínas, como Filis, Fedra, Énone, Dido, Deyanira, Cánace, Laodamía o Hero, acabaron con su vida ahorcándose o, más frecuentemente, atravesándose el pecho con una espada o cuchillo. Este último fue el instrumento con el que se suicidó Lucrecia, personaje histórico-legendario, esposa de Colatino Tarquinio, tras ser violada por un pariente de su marido llamado Sexto Tarquinio, hijo del séptimo y último rey de Roma, Tarquinio el Soberbio, acto criminal que dio lugar a la venganza de los familiares y amigos de aquélla y que provocó el cambio del régimen monárquico por el republicano según la tradición en el año 509 a. C., con la consiguiente expulsión de Roma del rey y de toda su familia.

Distinta fue la muerte de otra mujer, ésta realmente histórica, la cartaginesa Sofonisba, hija del general Asdrúbal, casada primero con Sífax, rey de los númidas y aliado de los cartagineses, la cual, tras la derrota de su esposo por las tropas romanas en el año 203 a. C. y ante la disyuntiva de convertirse en esclava de éstos o morir con dignidad, tomó la firme y resuelta decisión, impropia de una joven de apenas quince o dieciséis años, de tomar la copa de veneno que su segundo marido, Masinisa, aliado de los romanos, le envió por medio de un mensajero.

No cabe duda de que tanto Lucrecia como Sofonisba pasaron a la historia por la fuerza de su carácter, que les impulsó al suicidio para preservar su castidad, su honra y buena fama en el caso de la primera, y su libertad, dignidad y patriotismo en el de la segunda. Pero además de su fortaleza de ánimo, de su carácter resolutivo, de su valentía, estas dos mujeres debieron de poseer una gran belleza y, sobre todo, un porte especial que las convertía en objetos de deseo. Francesco Petrarca en sus Epístolas Familiares (18.7.1-4) nos dice que esas dos mujeres, juntamente con Cleopatra y Fedra también suicidadas, debieron de resultar muy atractivas y deseadas por un serie de detalles, entre los que se encontrarían su pudor, su voz trémula, su cabello desme- 
lenado, su cintura desceñida, sus pies desnudos, su toga colocada con improvisación y a menudo su porte un tanto descuidado en lugar de un atuendo suntuoso. Con tales prendas pudo la vencida Sofonisba enamorar perdidamente, según Petrarca, al vencedor Masinisa (talem fuisse Sophonisbam reor, dum Masinissam cepit victa victorem) y lo mismo le ocurrió a Lucrecia, quien a pesar suyo inflamó de furiosa pasión el corazón del joven Sexto Tarquinio, hecho que puso fin a la monarquía y fue el origen de la libertad romana, es decir, de la República (talis, puto, Lucretia erat, dum Sexti Tarquinii pectus accendit, unde regnorum finis et romane libertatis exordium fluxit).

Los escritores de la Antigüedad prestaron, como era de esperar, un gran interés a la historia de Lucrecia, que al fin y al cabo estaba detrás del mito del origen de la República, y sobre ella escribieron tanto escritores griegos: Dionisio de Halicarnaso (Antiquitates romanae, 4.64-67), Diodoro Sículo (Bibliotheca Historica, 10.20), Dión Casio (Historia romana, fr.II.11.13-19), Plutarco (Parallelae siue Vitae illustrium uirorum, Publicola, 1.3); como latinos: Varrón (De lingua latina, 6.6-7), Cicerón (De republica,2.20; 5.22-23), Valerio Máximo (Factorum et dictorum memorabilium libri, 6.1.1), Eutropio (Breuiarium ab urbe condita, 1.8), Claudiano (In Eutropium liber prior, 18.446-447, Laus Serenae, 149-154), San Jerónimo (Aduersus Iouinianum, 1.46). Con todo, los escritos de autores de la Antigüedad clásica y tardía sobre la violación de Lucrecia, que han tenido más repercusión en la posteridad, fueron en primer lugar el amplio y completo que nos ofrece el historiador Tito Livio (Ab urbe condita, 1.57-60), el también extenso y completo que para celebrar el día del Regifugium, es decir, 'La huída del rey', escribió el poeta Ovidio en el libro segundo de sus Fasti (vv.721-852) y el muy crítico sobre la decisión tomada por Lucrecia de San Agustín (De ciuitate Dei, 1.19). Los dos primeros, por encima de sus inevitables diferencias de tono, presentan, según Antonella Borgo (2011, pp.43-47), «una affinità nella struttura e, in qualche caso, nella scelta terminologica». La reconstrucción que el historiador y el poeta nos ofrecen del episodio se desarrolla según dos orientaciones, a saber, una primera que tiende a salvar el honor de Lucrecia y la honorabilidad de su marido transfiriendo el suceso del plano personal al público, de modo que la violencia ejercida por Sexto Tarquinio no es más que un reflejo de los abusos de un régimen injusto encabezado por su padre, Tarquinio el Soberbio, al que le tiene sin cuidado la dignidad del pueblo romano.Y una segunda, sobre todo visible en Ovidio, que presta una atención particular a la dimensión psicológica-emotiva de los protagonistas, la fogosidad de Sexto Tarquinio, la defensa de la castidad de Lucrecia, quien no solo se castiga a sí misma sino que exige a sus familiares y amigos que venguen su afrenta, una más de las que continuamente sufren en particular las mujeres y en general el pueblo romano. El relato de la violación de Lucrecia y del nacimiento de la República se articula en Tito Livio, y también en Ovidio, de acuerdo con las siguientes fases señaladas para el primero de ellos por S. Fontanarosa (1999, pp.115): 1) episodio del muliebre certamen; 2) acto de violencia cometido por Sexto; 3) confesión y suicidio de Lucrecia; 4) su muerte, que ocasiona los sucesos que sancionan el nacimiento de la República romana.

Mientras que Tito Livio y Ovidio consideran a Lucrecia como una heroína de la libertad que el pueblo romano alcanzó a comienzos del siglo VI a. C., San Agustín 
aborda la violación de Lucrecia y su suicidio desde el punto de vista de la moral cristiana, en la que prima sobre todo el derecho y el deber a la vida, y por lo tanto para él esa mujer no merece ninguna alabanza si se la compara con las mujeres cristianas que, habiendo sufrido violencia de los bárbaros de Alarico durante el saqueo de Roma en el año 410 d. C, decidieron continuar viviendo (De ciuitate Dei, I, 19,10): «ni en sus personas vengaron el crimen ajeno, por no añadir a la maldad de los otros la propia maldad, si porque los enemigos con apetito bestial cometieron en ellas estupros, ellas, por mal entendido rubor, perpetraran en sí mismas homicidios. Ellas, pues, en el más íntimo retiramiento de su ser, conservan el lauro de la castidad, el testimonio de su conciencia; y consérvanlo delante de los ojos de su Dios y ya no piden más, ni les queda ninguna otra cosa por hacer, como no se aparten de la autoridad divina, a la par que evitan el escándalo de la sospecha humana» ${ }^{1}$.

Por lo que se refiere a Sofonisba, trazos importantes de su breve vida, pues murió cuando apenas había sobrepasado los quince años, nos los ofrecen unos pocos escritores de la Antigüedad clásica, entre los que se encuentran dos autores griegos, Polibio (Historiae, XIV, 7-9) y Apiano (Historia Romana, VIII, 26-28), y sobre todo Tito Livio, quien dedicó el capítulo 23 del libro XXIX de la mencionada $A b$ urbe condita a relatar la entrega de la jovencísima Sofonisba a Sífax, antiguo aliado de los romanos, compromiso matrimonial que sellaba también una alianza política y militar entre Cartago y el rey de los númidas, y los capítulos 12-15 del libro XXX a narrar la derrota de Sífax por otro númida, Masinisa, quien se apodera de su capital, Cirta, y se encuentra por primera vez con la bellísima Sofonisba, la cual le implora que no la entregue como esclava a los romanos y, si esto no le es posible, que la libere con la muerte. El joven Masinisa no puede resistirse ante tanta belleza y juventud y cae perdidamente enamorado de ella, hasta el punto de ordenar el inmediato casamiento, pero sin darse cuenta de las consecuencias que dicha decisión conllevaba, pues cuando se presentó ante su general en jefe, Escipión, llamado más tarde el Africano, éste le recriminó su proceder y le ordenó que le entregase a la joven reina para ser llevada a Roma como esclava junto con el botín de guerra. Sin embargo, Masinisa, entre la orden de su comandante y la petición que le había hecho Sofonisba de que la liberase de la arbitrariedad de los romanos con la muerte si no tenía otra opción, decidió enviarle por un mensajero una copa con veneno, que ella con gran sentido de la dignidad y fortaleza de ánimo bebió muriendo al instante.

Era de esperar que con la llegada del Humanismo renacentista creciese y se difundiese el interés por personajes tan atrayentes y emblemáticos (heroínas de la libertad y del patriotismo) como Lucrecia y Sofonisba, y así fue, pues Petrarca en su epopeya latina titulada Africa $^{2}$ dedicó el libro V, que contiene 773 versos, a relatar con toda clase de detalles cómo la hermosura de Sofonisba cautivó el corazón de Masinisa des-

\footnotetext{
${ }^{1}$ Cf. San Agustín La Ciudad de Dios, Libros I-II, traducción de Lorenzo Riber (1953: 44).

${ }^{2}$ Utilizamos la edición Pétrarque, L'Afrique,1338-1374 de Rebecca Lenoir (2002) y, para el libro V, la más reciente Francesco Petrarca, La lira y el laurel. Poesía latina selecta, edición bilingüe de Alicia de Colombí-Monguió (2013).
} 
de su llegada al palacio de la reina y cómo éste tuvo que resolver el conflicto que se le planteaba entre seguir el camino de la virtud y la razón, exigido por Escipión, o el de la pasión amorosa, resuelto en este mismo libro a favor del primero con el envío del veneno y el posterior suicidio de Sofonisba, reservando los 80 primeros versos del libro VI al descenso de esta última a los Infiernos. No hay duda alguna de que las partes esenciales o episodios de la trama narrativa proporcionados por el relato de Tito Livio han sido escrupulosamente respetados por Petrarca, si bien en muchos casos han sido amplificados. Pero sorprendente y contrario al espíritu y a la letra de lo que la historia del historiador romano dice de Sofonisba, nos parece lo que expone Petrarca al comienzo del libro VI (vv.1-80) cuando la reina llega a los infiernos y es juzgada por los tres jueces de aquel lugar, a saber, Minos, Radamante y Éaco, quienes en principio no se ponen de acuerdo sobre la ubicación a la que deberá ir destinada, pues el primero propone la cárcel segunda asignada a los suicidas, propuesta que comparte también Radamante, pero Éaco disintió de este fallo y propuso otro que tuvo la aprobación del mundo de las sombras y que fue el definitivo, a saber, que se la llevase al tercer recinto, el de los enamorados, pues como justifica el último juez: ${ }^{3}$ «Es el amor la causa de su muerte; forzada abandonó la vida». Es posible que el mismo gran poeta italiano se percatase de lo inverosímil que resultaba una Sofonisba enamorada, tierna y dócil a su marido, frente a la imagen que Tito Livio ofrece de ella como una mujer orgullosa, resuelta, fanatizada en su patriotismo, distante y fría en todo momento respecto a Masinisa, al fin y al cabo un enemigo de su patria, pues los versos 74-80 están dedicados a reflexionar sobre la general consternación producida al propalarse la noticia de la muerte de una mujer que demostró ${ }^{4}$ «un coraje inmenso ante una muerte cruel, coraje digno de ser admirado por los hombres».

Otro gran escritor italiano, Giovanni Boccaccio, relató siguiendo a Tito Livio la historia de Lucrecia en dos de sus obras, el De casibus uirorum illustrium (3.3: De Tarquinio Superbo, Romanorum rege) y el De claris mulieribus (48: De Lucretia Collatini coniuge). En esta última obra también dedicó un capítulo a Sofonisba (70: De Sophonisba regina Numidie), en el que traza una escueta semblanza inspirada de nuevo en Tito Livio, al que compendia siguiéndole paso a paso en todos los capítulos dedicados a Sífax, Masinisa y Sofonisba, si bien omite el que se refiere a la entrevista del primero con Escipión y por lo tanto las palabras pronunciadas por aquél advirtiéndole del peligro que su esposa representaba en el futuro para Roma si ella permanecía libre al lado de Masinisa.

En nuestro rápido recorrido sobre los más relevantes autores que se han ocupado tanto de Lucrecia como de Sofonisba, hemos llegado a los primeros y más excelsos humanistas italianos, Petrarca y Boccaccio, y es el momento de recordar que estos autores, lo mismo que los que continuaron su labor de recuperar o hacer renacer el legado de la Antigüedad clásica, se debatieron entre su pasión por la cultura clásica, pagana al fin y al cabo, y sus propias convicciones cristianas, que de alguna manera

\footnotetext{
${ }^{3}$ Cf. Africa, 6.20: Mortis amor causa est, lucemque coacta reliquit.

${ }^{4}$ Cf. Africa, 6.79-80: hunc ingens duro constantia leto/ feminea et nulli non admiranda uirorum.
} 
les impedían apreciar en toda su dimensión la decisión de Lucrecia, e incluso de Sofonisba, mujeres que al darse a sí mismas la muerte contravenían, como hemos dicho, el precepto cristiano del derecho y deber a la vida. Y así, mientras San Agustín mostraba su oposición radical al suicidio de Lucrecia, los humanistas tuvieron que obviar de alguna manera esta cuestión moral para apreciar el valor que para ellos representó Lucrecia como heroína de la libertad y defensora de la castidad o Sofonisba como ejemplo de patriotismo, fortaleza de ánimo y dignidad personal. A medio camino entre la pasión por la cultura pagana y su adaptación a los preceptos de la moral cristiana, se encuentra la pieza retórica titulada Declamatio Lucretie, compuesta en torno a 1370 por otra gran figura de la segunda generación del Humanismo italiano, Coluccio Salutati ${ }^{5}$ (1332-1406). Su posición de compromiso entre lo pagano y lo cristiano queda bien reflejada al analizar las fuentes en las que bebió este humanista, como demostró Enrico Menestò (1979, pp.920-922); en lo que se refiere a los autores de la Antigüedad clásica, fueron Ovidio y sobre todo Tito Livio en los que se inspiró: «Il testo del Salutati, infatti, no solo si presenta spesso come la parafrasi delle parole liviane, ma ricorda anche moduli ovidiani». Por otra parte, Salvatore Fontanarosa (1999:138-139) ha tenido el acierto de señalar que, además de Tito Livio y Ovidio, Salutati es deudor de varias expresiones e ideas que aparecen en el mencionado capítulo I, 19 del De ciuitate Dei de San Agustín. Con todo, las semejanzas entre la pieza retórica de Salutati y el capítulo del obispo de Hipona, no parecen sugerir en general, sostiene Fontanarosa, una adhesión del primero a la polémica levantada por el segundo: «Salutati sembra preoccupato soprattutto di arrichire di spunti dialettici il dibattito tra Lucrezia e i familiari impegnati a fugare i propositi suicidi della donna. Lo sforzo di conferire enfasi al discorso di Lucrezia finisce, però, per sortire effetti inaspettati, con deformazioni, per alcuni versi anche grottesche, del senso e dello spirito dei modelli antichi; lo testimoniano le argumentazioni, alquanto capziose, addotte dal l'eroina a sostegno della decisione di rinunciare alla vita.... Come si è visto, la Lucrezia del Salutati, se da una parte resulta tragicamente consapevole dell'irrimediabilità dell'offesa subita, dall'altra arriva persino a dichiarare di temere l'eventualità di potersi assuefare con piacere alla pratica dell'adulterio».

Antes de abordar la presencia de textos referentes a Lucrecia y Sofonisba en la Castilla de la primera mitad del siglo $\mathrm{XV}$, debemos resumir lo hasta aquí expuesto señalando que entre la Antigüedad y los comienzos del Renacimiento italiano, dejando aparte a Ovidio, tres fueron los autores cuyos relatos sobre Lucrecia gozaron de más predicamento entre los lectores y hombres de letras europeos, a saber, Tito Livio, San Agustín y Coluccio Salutati; sobre Sofonisba se impuso, por lo menos hasta finales ${ }^{6}$

\footnotetext{
${ }^{5}$ Sobre este humanista, además de las fundamentales monografías de B. Ullman (1963) y de R. Witt (1983) puede consultarse el amplio y atinado capítulo que le dedica Guido M. Cappelli (2007, pp.58-69); obra recientemente traducida al italiano y actualizada bibliográficamente (2010, pp.76-88)

${ }^{6}$ Respecto a los escritores de la Antigüedad, hasta finales del siglo XV la historia de Sofonisba se basa exclusivamente en la versión de Tito Livio y sólo a partir del siglo XVI es cuando se conoce el texto de Apiano, que difiere de aquel al dar por sentado que Masinisa y Sofonisba habían estado prometidos y enamorados, y por razones de Estado la joven fue prometida al viejo Sífax.
} 
del siglo XV, el relato de Tito Livio y, en menor mediada, el libro V y los ochenta primeros versos del VI del Africa de Petrarca, pues, como hemos dicho, el capítulo que Boccaccio le dedica en De claris mulieribus, es cieramente un resumen de Tito Livio.

\section{EL SUICIDIO DE LUCRECIA SEGÚN ALFONSO DE MADRIGAL}

Así las cosas, la pregunta que debemos formular es si estos autores y sus correspondientes obras fueron conocidos en Castilla a lo largo de la primera mitad del siglo XV. La respuesta ha de ser desde luego afirmativa, tanto en lo que corresponde a la circulación y lectura por parte de letrados de los textos latinos como a su traducción castellana más o menos próxima a los modelos humanísticos, por medio de la cual podían los desconocedores o poco conocedores de la lengua del Lacio acceder a la comprensión del mensaje. A tenor de la concepción tradicional del acendrado catolicismo español, de la estrecha vinculación de los españoles a los autores cristianos mucho más que a los paganos desde la misma caída del Imperio romano, en el caso de Lucrecia esperaríamos que se impusiese aquí la visión cristiana de San Agustín sobre la pagana de Tito Livio o incluso la 'humanista' de Salutati. Lo cierto es que los autores castellanos que han escrito sobre esta mujer, salvo una excepción que comentaremos a continuación, no dejan de mencionar nominalmente al obispo de Hipona, pero el relato que siguen es casi siempre el de Tito Livio y ocasionalmente el de Salutati.

Merece la pena detenernos en esa excepción que explica el suicidio de Lucrecia siguiendo a San Agustín, quien, como hemos anticipado, había rechazado el proceder de la mujer pagana y defendido el de las mujeres cristianas, que también habían sido violadas, no sin antes formular una obvia premisa general, a saber, que en los casos de violación la culpa es del violador y no de la mujer forzada, que en modo alguno ha consentido con quien la poseyó. Sin embargo, ¿cómo es posible que Lucrecia, tras ser violada, se diese la muerte sin ser culpable? La contestación es que el suicidio es de por sí inaceptable, tanto si se la considera honesta (inocente) como adúltera (culpable). Ahora bien, dados estos dos supuestos, se pregunta ${ }^{7}$ nuestro autor por qué es alabada si se la considera adúltera, y por qué se mató si era honesta. Así pues, la explicación de la muerte de Lucrecia no se obtiene partiendo de esta dualidad (pudica) adultera), que se refiere al ámbito corporal, sino en el plano espiritual de una mujer cuya mayor debilidad es ${ }^{8}$ «no soportar la vergüenza de la torpeza ajena que en ella se ejecutó, aunque no con ella, una mujer romana ávida en exceso de gloria, que prefirió matarse porque no se pensase que lo que había padecido con violencia en vida lo hubiera padecido con agrado suyo si siguiera viviendo. Por esta razón, pensó que debía

\footnotetext{
${ }^{7}$ Cf. De ciuitate Dei, I, 19,7: Si adulterata, cur laudata; si pudica, cur occisa?

${ }^{8}$ Cf. De ciuitate Dei, I, 19, 9: Puduit enim eam turpidinis alienae in se commissae, etiamsi non secum, et Romana mulier, laudis auida nimium, uerita est ne puteretur, quod uiolenter est passa cum uiueret, libenter passa si uiueret.Vnde ad oculos hominum testem mentis suae illam poenam adhibendam putauit, quibus conscientiam demonstrare non potuit.
} 
ofrecer a los ojos de los hombres a quienes no pudo demostrar su conciencia, aquella pena como testigo y expresión de su voluntad».

El miedo a la mala fama, al deshonor, al qué dirán, es la motivación constante del comportamiento de Lucrecia no sólo del suicidio, sino también, como acertadamente señala Antonella Borgo (2011, pp.52-53), de su consentimiento a una violencia a la que no le habían doblegado ni la declaraciones de amor, ni las promesas o intimidaciones de Sexto Tarquinio, y a la que sólo cede ante la amenaza del deshonor. Pues bien, la explicación de San Agustín sobre el suicidio de Lucrecia se recoge en el capítulo 112 del Breviloquio de amor e amiçiçia de Alfonso de Madrigal, El Tostado, que por su gran interés y por permanecer hasta el momento inédito, ${ }^{9}$ reproducimos completo siguiendo el manuscrito 2178 de la Biblioteca Universitaria de Salamanca, folios $59^{\mathrm{v}}-60^{\mathrm{r}}$ :

/f.59va/De la differençia del bien de la fama e de la honrra e si es obligado el virtuoso alguna vez dexar perder la fama por los amigos (in marg.).

De la fama que es buen nombre es dolor de virtud, paresçe seer más duro que de todos los susodichos, ca todas las cosas susodichas pertenesçen a los bienes de la fortuna, los quales non tienen algún ayuntamiento con la virtud o tienen poco. La fama o el buen nombre aunque non sea virtud nin acto de virtud, enpero ella viene en pos de la virtud et nobles fechos. Echar de sí el buen nombre es consentir que nuestra fama sea manzillada, conviene saber, dexar que tengan por ombre malo o de mala condiçión por salvar al amigo. Cerca de lo qual, aunque esta fama paresca seer de los bienes muy grandes, alguno determinará que por el amigo de despreçiar avemos la fama ansí commo despreçiamos las honrras. Que por el amigo ayamos las honrras de menospreçiar, determínalo Aristotiles en lo susodicho: la fama e la honrra a una misma cosa pertenesçen; commo nos digamos la honrra seer reverençia dada por la virtud, fama es de las virtudes de alguno o de nobles fechos, oppinión conçebida e publicada por boca del pueblo. Pues ambas pertenesçen a la virtud e ansí si dixéremos que /f.59vb/ la honrra deve seer por el amigo despreçiada e del todo desechada, non paresçe aver alguna razón por la qual non devamos semejante la fama despreçiar. Et esto es de responder que non es conveniente argumento, ca la fama e la honrra tienen entre sí grande differençia, ca honrras llaman aquí algunos prinçipados o poderíos a los quales está anexo grande honrra. Estas dignidades et poderíos se cuentan en los bienes contençiosos de la fortuna, pues ansí commo todas las otras cosas son de dexar et del todo menospreçiar por el amigo, ansí sin alguna dubda es de decir de estas cosas e a esta honrra podemos libremente renunçiar et dexar. Otra honrra es la qual dezimos seer reverençia dada en testimonio de virtud e ésta es más conjuncta con la virtud que la dignidad o el poderío. A ésta non podemos nós libremente renunçiar porque non es bien de nos posseýdo nin quasi posseýdo e aunque nós non queramos e aunque fuyamos, si fuéremos buenos nos serán dadas grandes honrras de los varones virtuosos, ansí commo contesçía a los sanctos, los quales en quanto más fuýan de las honrras más los honrravan. Enpero, si aun podiéssemos a esta honrra renunçiar o dexarla, más aýna la devríamos dexar que a la fama, ca aunque non fuésemos honrrados

\footnotetext{
${ }^{9}$ No lo hemos encontrado en ninguno de los libros que editan partes de esta obra, desde el de Pedro Cátedra (1987) al de Nuria Belloso (2000). Por lo demás, Pedro Cátedra dedica dos interesantes capítulos al Breviloquio como obra literaria en su estudio Amor y pedagogía (1989, pp.17-39).
} 
podríamos seer tenidos por virtuosos et non será tirada nuestra buena fama; enpero, si nós dexamos la fama, la buena oppinión que de nos tienen será manzillada, mas ante seremos despreçiados ansí commo aquellos que seyendo verdaderamente malos avíamos fingido seer virtuosos trayendo en nos una semejança suya. Pues non ha algún bien que más grave sea de dexar que la oppinión de nos concebida tienen que seamos virtuosos et esta llaman fama. Onde algunos entre los antiguos aunque fuesen amadores de la virtud e zeladores de ella, enpero en algunas cosas más a la fama que la virtud preçiaron. Ansí paresçe de Lucreçia, la qual se pone ansí commo flor de las mujeres romanas; a la qual commo Sexto Tarquinio, fijo de Tarquinio el sobervio el qual era entonçe rey de los romanos e fue séptimo et postrimero, soliçitasse a adulterio, de la qual fuera en su posada una noche acogido porque era pariente de su marido Colatino, pasadas munchas blanduras de amadores e munchas ame/f.60 ra/nazas estovo firme, e quando él apretando la espada paresçía que degollarla quisiesse, sin temor por guardar la castidat esperava la muerte escogiendo más de la vida que de la castidat seer privada. Et commo con estas artes de engaño de su mal conçebimiento alguna desseada salida non viesse, amenázala diciendo que la mataría e ençima del lecho de su marido pornía con ella un siervo de su casa degollado para que esto fuesse testimonio a su marido Colatino et a todos los otros romanos que ella en adulterio moriera. En lo qual ella llagada de un muy estraño dolor, la fama de sus virtudes en esto seer manzillada, la qual ella tenía speçial ntre las dueñas romanas, qué escogiesse non sabía, a la fin aunque non complidamente consintió a Sexto Tarquino, soliçitador de adulterio. Este peccado ligeramente encobrirse podiera e aunque su marido lo supiera la perdonárala; enpero, porque amava la virtud, en el día siguiente faziendo llamar a su marido, el qual entonçe fuera de la çibdad en la pelea estava, e a su padre, veyendo con gran amargura de su coraçón contado en lágrimas lo que fecho avía, conçibiendo desseo de morir, tenía so su vestidura un cuchillo ascondido en señal de adulterio padesçido contra su voluntad et con llorosas palabras poniendo término en su narraçión feriéndose varonilmente con el escondido cuchillo cayó muerta. De lo qual Tito Livio en el primero libro Ab urbe condita et Augustino en el libro De ciuitate Dei, libro primero, capítulo XIX. Esta Lucreçia, la qual entre las romanas mujeres muncho es ensalçada, aunque a la virtud amasse, enpero a la fama más preçió escogiendo más que la virtud peresçiesse que la fama. Enpero esto viene del non complido desseo de las virtudes, ca el que verdaderamente ha la virtud commo ella sea mejor que todos los otros bienes judgará que ella más se deve amar que todas las otras cosas e quando dan a escoger que aya de peresçer uno u otro más avemos de escoger que peresca qualquier que la virtud resçiba algún dapño. Pues por el amigo la fama ansí commo todos los otros bienes avemos de dexar, ca más es de escojer por el amigo justamente la nuestra oppinión seer manzillada quedando a nos siempre la verdadera virtud que a nos, quedando la fama, la virtud resçiba dampno./f. $60^{\mathrm{rb}} / \mathrm{S}$. Si alguno veyendo a su amigo puesto a la muerte o a grandes peligros non lo libra por miedo de perder su buena fama, faze contra ley de los amigos e non tiene entrañas de amor nin puede conservar la verdadera virtud. Pues neçessario es que el onbre veniendo a tal estrechura pierda la verdadera virtud quedando la buena fama de virtudes, o perdida la fama tenga la verdadera virtud e mayor que ante era; enpero si alguno escoja más la fama que la virtud non es amador de la virtud, pues la fama ansí como todos los otros bienes dexará el virtuoso por su amigo, et non hay alguna cosa la qual non dexe perder el virtuoso por su amigo salvo la verdadera virtud, en la qual los amigos tienen permanençia et por ésta fueron fechos amigos, en ésta non ay algún movimiento, ca el virtuoso non dexará la virtud por su amigo nin el amigo esto 
demandará, e aunque alguno de estos amigos quisiesse por amor de otro amigo fazer algunas cosas las quales fuesen contra la virtud, el otro non lo consentiría. Ansí lo dize Aristótiles en el octavo de las Éthicas: Los amigos virtuosos son para permanesçer según sí mesmos et permanesçe uno con otro et non han menester que uno por otro faga mal nin alguno de ellos lo fará, mas según manera de fablar ante lo vedará, ca a los buenos pertenesçe que ellos non pequen nin dexen a otros pecar por amor de ellos.

Como podemos observar por la lectura de este capítulo, El Tostado tiene en cuenta el relato de Tito Livio, al que cita junto con San Agustín, pero es en éste último en el que se inspira para poner a Lucrecia como un claro ejemplo de cómo la virtud cedió ante el afán de gloria, de fama, pues aunque esta mujer no dejó de ser virtuosa, «enpero a la fama más preçió escogiendo más que la virtud peresçiesse que la fama».

\section{EL RELATO DE TITO LIVIO SOBRE LA VIOLACIÓN DE LUCRECIA}

Ya hemos dicho que Alfonso de Madrigal suponía una excepción en el tratamiento de la violación de Lucrecia, pues otros autores que tocaron dicho tema no dejan ciertamente de citar a San Agustín, pero no se hacen eco de su explicación y de su oposición, pues lo que les interesa es la descripción de los hechos ocurridos cuya fuente principal sigue siendo Tito Livio. Es el caso del Marqués de Santillana, quien se sintió interesado por esta heroína, a la que citó entre las mujeres hermosas en el proverbio 54 (v.427) de su obra Proverbios o Centiloquio, y a la que dedicó dos glosas, una, breve, al citado proverbio y otra, más amplia, en el proverbio 40 al referirse a Tarquinio el Soberbio (v.319). En la primera de las glosas ${ }^{10}$ el Marqués cita a Tito Livio, Valerio Máximo, el De ciuitate Dei de San Agustín, y las obras de Boccaccio De casibus y De preclaris mulieribus y se limita a decirnos que Lucrecia fue forzada por Sexto Tarquino, por cuya causa se mató con un cuchillo o una espada pronunciando estas últimas palabras: "Yo soy quita de culpa mas non de pena». Por lo demás, nuestro autor justifica la brevedad de la glosa porque en un provebio anterior (el 40) se había explayado sobre el tema. En efecto, en la glosa que le dedica al último rey de Roma vuelve a citar a Tito Livio, San Agustín, Valerio Máximo y Juan de Gales, si bien la extensa narración (Gómez Moreno-Kerkhof 1988, pp.236-238) procede del primero y nos atreveríamos a sugerir que concretamente de la traducción que de las Décadas de Tito Livio había llevado a cabo en los primeros años del siglo XV Pero López de Ayala, a partir de la que había hecho en francés Pierre Bersuire entre 1354 y 1356 y de la que tenía varios ejemplares en su biblioteca. En efecto, correspondiente a la Primera Década y procedente de dicha biblioteca, se conserva en la Biblioteca Nacional de Madrid un voluminoso manuscrito, el 10.802, ff. $31^{\mathrm{v}}-32^{\mathrm{v}}$, y aunque Curt J. Wittlin (s.a., pp.368-373) ha realizado una magnífica y rigurosa edición, creemos que merece la pena reproducir el pasaje de Lucrecia (Ab urbe condita 1.57-59), tal

\footnotetext{
${ }^{10}$ Utilizamos la muy buena edición de Ángel Gómez Moreno y Maximilian P. A. M. Kerkhof (1988, pp.243-245).
} 
como lo leyó el Marqués y que con toda probabilidad le sirvió, junto alguna otra lectura, para realizar las mencionadas glosas:

[Madrid, Biblioteca Nacional, Ms. 10.802, ff. $31^{\mathrm{v}}-33^{\mathrm{r}}$ ]

$<$ Episodio del muliebre certamen $>$

/f.31 vb/Los romanos provaron si la dicha çibdat (=Ardea) se podría tomar por conbatirla luego, mas desque vieron que poco les podría aprovechar, ellos la çercaron, e fiziéronla toda enderredor çerrar porque non saliese alguno. Mas commo muchas vezes acaesçe en las guerras que los lugares que se çercan, más es el detenimiento del tienpo que el peligro de batalla; e aquellos de la hueste avían asaz espaçio e lugar de ir a sus casas e tornar, espeçialmente los cabdillos e omnes ricos, más que los cavalleros que guerreavan. Donde acaesció así que los omnes mançebos del rey algunas vezes, por pasar su enojo, fazían sus conbites los unos a los otros. E así avino que estava un día en la tienda Sexto Tarquino, e estava con él un noble omne de Roma que llamavan Collatino; e Tarquino Sexto que çenava con ellos movió una questión de sus mugeres, diziendo quál d'ellas era más noble en costunbres; e cada uno alavava la suya maravillosamente. Collatino dixo que d'esto non avía por qué fablar mucho, que aína lo podían fazer saber e ver por isperençia que çierto era que Lucresçia, su muger, era mejor que ninguna de las otras: «E nós podemos luego provar que somos mançebos; cavalguemos e vamos para Roma así súbitamente, por ver qué fazen nuestras mugeres que están agora sin sospecha de nuestra ida e así sabremos de cada una en qué estado la fallaremos». El consejo de Collatino plogo a cada uno d'ellos, e les paresçió bien por quanto lo dixo así sin grant deliberaçión; e por ende los mançebos, que estavan escalentados del vino del su convite, cavalgaron en sus cavallos e se van a Roma; e llegaron allí a la ora de primero sueño, quando la noche començava a çerrarse. E dende fueron a Colasçia, do era la posada de Collatino, e fallaron a Lucresçia, su muger, en otro asentamiento do avían fallado las otras nueras del rey, las quales fallaron jugando e tomando plazer, e pasando así su tienpo con otras conpañeras en conbites e solases; e a Lucresçia fallaron que fazía su ofiçio, filando, e asentada entre sus mugeres velando la noche. E así que Lucresçia ovo entre ellos el loor de las dueñas e la aventaja, e fue judgada por la mejor. E por ende su marido Collatino, como aquel que ovo la vitoria, convidó a los otros por plazer que avía; e los parientes del rey mançebos que aý eran fueron acogidos e resçibidos por Lucresçia muy graçiosamente. Mas por çierto, en aquel conbite, grande ardor de luxuria le ençendió a Sesto Tarquino de amores de Lucresçia, e luego pensó de la aver, o por /f.32 ra/ fuerça o por otra manera; a la qual cosa mucho le enamorava la fermosura e la onestidat de Lucresçia. Quando los mançebos fijos del rey se partieron de aquel solaz de aquella noche e se tornaron a la hueste, commo estavan primero.

\section{$<$ Violación de Lucrecia por Sexto Tarquinio $>$}

Dende a poco tienpo después d'esto, Sesto Tarquino, sin lo saber Collatino, con un solo conpañón se fue para aquel lugar do está Lucrescia; e fue muy cortesamente de las gentes de Collatino < resçibido $>$, como aquellos que non sabían cosa de su venida 
nin de su mala entención. E así fue que, después que ovo allí çenado, leváronlo a una cámara do tenía fecha su cama. E quando él vio que todos eran adormidos, e él estava todo ardiendo e enflamado del amor de Lucresçia, fue a la cámara do ella dormía; e levava en su mano derecha un cuchillo desnudo, e la mano siniestra puso sobre el pie de Lucresçia, e le dixo estas palabras: « ¡Cállate, dixo, Lucresçia! Ves aquí el cuchillo con que yo to mataré si una palabra fablas solamente». Commo Lucresçia oviese miedo, e commo adormida veía la muerte así aparejada, e sin persona alguna que le pudiese valer nin ayudar, e Tarquino de la otra parte le requiría de su amor e la rogava e la menazava que se esforçase en todas guisas de inclinar el su femíneo coraçón de dueña. Finalmente él la fallo así fuerte, en su castidat así dura e porfiada, que por menazas nin por espantos de muerte non la enclinava; estonçe ayuntó con el miedo que le ponía verguença, e díxole que si ella non fiziese a su voluntad, él non la mataría así sola, mas que mataría un su siervo que allí estava e a ella, e los ayuntaría en uno desnudos, e que diría que los matara por quanto los fallara en adulterio. Esta vergueña espantó mucho a Lucresçia, así que la luxuria vençió a la castidat porfiada; e Tarquino fizo d'ella su voluntad. El qual luego, muy alegre e pagado por quanto él avía engañado la fermosura de la dueña, se tornó a la hueste. E Lucresçia fue muy triste d'este grant mal que ella avía fecho, e luego enbió a /f.32 rb/ Roma un mensagero a su padre, e otro a Ardea, donde estava su marido en la hueste; e enbióles dezir que cada uno d'ellos, con un solo conpañero, viniese a ella muy apresuradamente, ca así era menester, ca una cosa espantable le avía acaesçido.

\section{$<$ Lucrecia revela la violencia de Sexto Tarquinio y decide suicidarse $>$}

Su padre de Lucresçia, que avía nonbre Espurius Lucresçius, venía con un su amigo que llamavan Publius Valerius, fijo de Valesio; e su marido Collatino con Junius Brutus, de que suso diximos que se enfengía loco; estos dos fallaron el mensagero de Lucresçia en Roma ado ellos eran venidos, ca por aventura ellos ivan al lugar de Colates, ado estava Lucresçia, la qual fallaron en su cámara muy triste asentada. Las lágrimas le salieron quando ella vio amigos; e preguntóle su marido si las cosas de casa estavan bien e cómmo devían. Respondió ella: «Non, por çierto. ¿Qué cosa puede estar bien a la dueña, dixo ella, quando ha perdido su castidat? ¡Ha, Collatino!, dixo ella, en tu cama son pisadas de un omne estraño; mi cuerpo ha seído forçado e desonrrado, mas mi coraçón es innoçente, e la muerte me será d'ello testimonio.Mas por Dios, ¡dame la tu mano derecha e me jura tu fee que este adulterador aya su pena! Ca este, dixo ella, es Sesto Tarquino, que es venido a mí commo enemigo en lugar de huéspede; ca esta noche vino a mí todo armado e tiró de mí —e sí fizo a vos, si vós omnes sodes - todo plazer e bien». Los amigos que allí eran, todos por orden, le prometieron su fee; e confortavan su coraçón deziéndole que ella non avía culpa, pues fuera tomada por fuerça, e que la voluntad fazía el peccado e non el cuerpo, e que do non oviera consentimiento non avía culpa. Estonçe dixo Lucresçia: «Vós veredes aína qué es lo que omne deve al cuerpo que fizo maleficio; ca por verdad, si él es quito de peccado, por tanto non quiero yo que sea quito de pena; e yo non seré enxienplo que ninguna muger, que casta non sea, viva después de mí». E estonçe Lucresçia sacó un cuchillo que tenía deyuso de sus ropas ascondido e lo puso por su coraçón, e llegó la muerte luego sobre la llaga. 
$<$ La muerte de Lucrecia provoca la caída de la monarquía $>$

El marido e el padre se començaron a mirar. E en quanto ellos/f.32va/ así estaban, Bruto le tiró el cochillo de la llaga e lo tenía lleno de sangre que corría, e luego allí fizo un juramiento atal, diciendo en esta guisa: «Por esta sangre, dixo él, que está muy conprada delante la injuria real, que quiere dezir, después de la injuria fecha por el fijo del rey, yo juro y prometo a vós, los dioses, vos llamo en testimonio, que yo,por qualquier fuerça que yo podré, executaré e destruiré por fierro e por fuego a Tarquino el orgulloso, con su muger, cunplida de todos malefiçios, e todo su linaje d'ellos e de sus fijos, nin sofriré que ninguno d'ellos nin otros regnen d'aquí adelante más en Roma. El sobrdicho Bruto dio el cochillo a Collatino e a Lucreçio, el padre, e después a Publuis Valerius, el susodicho; así que ellos fueron maravillados de tal engenio dónde era nuevamente nascido en el coraçón del dicho Bruto; e prometieron essa mesma promesa así como el dicho bruto lo mandó. E todos, conbertidos en ira e en saña, siguieron al dicho Bruto, llamándolos él para destruir e confonder aquel regno de Tarquino. Estonçe sacaron el cuerpo de Lucreçia de su cas e lo levaron al mercado......

\section{LA DECLAMATIO LUCRETIE DE COLUCCIO SALUTATI VERTIDA AL CASTELLANO}

De la biblioteca del Marqués de Santillana procede también el manuscrito Vitr.144 de la Biblioteca Nacional de Madrid, que entre los folios $89^{r}-93^{r}(=\mathbf{M})$ contiene $^{11}$ la traducción castellana de la Declamatio Lucretie, en realidad, como afirma Enrico Menestò (1979:919), dividida en dos partes, una primera en la que el padre y el marido de Lucrecia tratan de disuadirla de la idea del suicidio, y una segunda en la que ésta sostiene la necesidad de su propia muerte, que en efecto lleva a cabo. Así pues, no ha de extrañarnos que el explicit de este manuscrito hable en plural de Declamaçiones (f. 93' : Fenesçen las Declamaçiones de Colluçio chançeller de Florençia çerca de Lucreçia). De la versión castellana, además del citado manuscrito de la Biblioteca Nacional, que, como dijimos, perteneció al Marqués de Santillana y muy probablemente fue traducido en su mismo círculo literario y a petición suya, conocemos otro testimonio ${ }^{12}$ que se encuentra actualmente en la British Library de Londres, ms. Add. 33.383, ff. $2^{\mathrm{r}}-5^{\mathrm{r}}(=\mathbf{H})$.

Según nuestra información, nunca se había prestado atención filológica a esta traducción castellana hasta estos últimos tres años, en los que han aparecido dos ediciones, una crítica apoyada en los manuscritos citados y teniendo en cuenta el original

\footnotetext{
11 Sobre la descripción de este códice pueden consultarse entre otros los siguientes trabajos: Mario Schiff (1970, pp.8-15); Charles Faulhaber et alii (http://sunsite.berkeley.edu/Philobiblon/BETA/2827.html).

${ }^{12}$ Cf. Charles V. Aubrun (1951, pp.V-VII: descripción del manuscrito; pp.1-6: trancripción de la Declamación de Lucrecia). Cf. también Mercedes Pampín (2002, pp.733-738). Este códice, que contiene el cancionero español de Herberay des Essarts, comienza con unas pequeñas obras en prosa, entre ellas, además de la Declamación de Lucrecia, se encuentra la Epístola de Madreselva a Mauseol, texto que tuvimos en cuenta en nuestra edición de las cartas originales de Rodríguez del Padrón (1984, pp.39-72), donde lo designamos con la sigla $\mathbf{H}$, que hemos mantenido en la nueva edición del Bursario (2010, pp.61-67).
} 
latino subyacente, llevada a cabo por una extraordinaria filóloga y gran conocedora de la literatura medieval española, María Morrás (2010, pp.209-247), aparecida en el merecidísimo homenaje que la revista norteamericana La Corónica ofreció al profesor Ottavio di Camillo; la segunda, una transcripción cuasi paleográfica del manuscrito de la Biblioteca Nacional de Madrid. Y mientras la primera sin olvidar al autor latino, el humanista Salutati, profundiza en el análisis de las versiones contenidas en cada uno de los testimonios manuscritos, la segunda, realizada por otra sobresaliente estudiosa, la italianista María de las Nieves Muñiz Muñiz (2012: 43-70), sin darse cuenta de que existía otro importante testimonio manuscrito y que ambos habían sido colacionados y analizados dos años antes por la citada María Morrás, enfoca el estudio de la versión castellana que le ofrece el manuscrito $\mathbf{M}$ bajo la premisa de que las traducciones de la literatura italiana en el Cuatrocientos español son la mejor prueba (201, p.43): «dello scarto che separava le due culture nel momento in cui l'Umanesimo latino incominciò a venire recepito nella Peninsola iberica». Además de ofrecer una aproximación al método de escritura empleado por el anónimo vulgarizador, intentando mostrar cómo la complejidad del texto latino del humanista italiano a duras penas y no siempre correctamente es plasmada en castellano, traza un valioso apunte sobre la leyenda lucreciana en el círculo del Marqués de Santillana.

Reconociendo estas valiosas aportaciones, y de modo especial la más estrictamente filológica de María Morrás, pretendemos ahora avanzar un poco más de lo que han hecho estas dos excelentes investigadoras, sobre todo porque el penoso estado en que se encuentran algunos folios del mejor de los testimonios, el manuscrito de la Biblioteca Nacional, ha propiciado que ambas filólogas, mucho más la italianista que la hispanista, hayan cometido errores de lectura que deben ser corregidos. Por lo demás, creemos que se puede ir más allá de lo que ha hecho María Morrás a la hora de hacernos una idea de cómo se desarrolló la tradición manuscrita, qué tipo de errores justifican la existencia de un arquetipo común a los dos testimonios castellanos y finalmente cómo debió ser el modelo latino que tuvo delante el anónimo autor de la traducción castellana. Antes de comenzar el análisis de estos aspectos de la tradición manuscrita de la versión castellana, quisiéramos recordar unas frases con la que comienza Curt Wittlin (2001, p.341) un espléndido estudio sobre los errores cometidos por traductores medievales:

Los filólogos que estudian traducciones medievales de textos conocidos tienen la ventaja, respecto a sus colegas que trabajan con obras originales, de saber, más o menos, lo que dijo el autor del texto traducido y lo que tendría que haber escrito el traductor. Contrastando el original con la versión, el investigador puede ver fácilmente si el traductor abrevió o alargó su texto de base, si introdujo cambios -sean de tipo estilístico o de contenido- o si cometió errores.

Pues bien, si como es bien sabido, la existencia de un arquetipo, es decir de una copia sacada directamente del original, puede demostrarse gracias a la presencia de uno o más errores significativos comúnmente compartidos por todos los testimonios de una obra, podemos adelantar que la tradición de la versión castellana nos 
ofrece un arquetipo común a $\mathbf{M}$ y $\mathbf{H}$ que llamaremos $\mathbf{X}$. Cabe la posibilidad de interpretar $\mathbf{X}$ también como el original salido directamente de las manos del anónimo traductor, en cuyo caso los errores que detectamos no serían del copista que fijó el escrito del traductor sino de este mismo. Sean atribuidos al traductor (=original) o al copista (=arquetipo), encontramos un primer error significativo que corresponde al capítulo 5 donde el texto latino dice: Vir, pater, Brutus et alii coniuncti que $\mathbf{X}$ lo interpretó así: «Tu marido e el padre Bruto e tus propincos», donde pater es unido a Brutus dando lugar a un error que a veces aparece en algunos autores medievales al considerar a Bruto como padre (o marido) de Lucrecia. Este error pasó tal cual a $\mathbf{M}$, pero $\mathbf{H}$ lo solucionó eliminando el artículo y el nombre de Bruto: «Tu marido e padre e tus más propinquos parientes». Un segundo error aparece en el capítulo 4, donde los manuscritos latinos ofrecen la lectura cara Lucretia traducida como "clara Lucreçia'; es decir el adjetivo carus, a, um 'querido' ha sido confundido con otro adjetivo parecido formalmente clarus, $a$,um 'claro, resplandeciente'. Encontramos en la traducción castellana dos omisiones de otras tantas frases latinas, que o bien ya faltaban en el original latino o, lo más probable, han de ser atribuidas al traductor o al copista de $\mathbf{X}$. Corresponden al capítulo 5: noli sola te ipsam qua uacas culpa damnare, y al capítulo 10: iam placebit adulter. Finalmente, en el capítulo 11 hemos conjeturado la palabra 'ánima', que aparece en el original latino y es omitida en la traducción. Así pues, en el vértice del estema tenemos un arquetipo del que descienden $\mathbf{M}$ y $\mathbf{H}$, pero mientras el primero lo hace de forma directa, $\mathbf{H}$ procede de él indirectamente, a través de un códice interpuesto, un subarquetipo, hoy desaparecido al que daremos la sigla z. La traducción que nos transmitió realmente $\mathbf{M}$, e hipotéticamente $\mathbf{z}$, se caracterizaba por la literalidad y por echar mano de uno de los modos (Buridant 1983, pp.119-122) de tratamiento de la materia textual, a saber, la amplificatio, compatibles ambas, como bien señala María Morrás (2010, pp.221224) con una tendencia fuertemente latinizante tanto en la sintaxis como, sobre todo, en el léxico a través del uso frecuente de la traducción de términos latinos por medio de una bimembración, en la que muy a menudo aparece un latinismo acompañando al vocablo castellano. Tanto $\mathbf{M}$ como muy posiblemente $\mathbf{z}$ debieron de copiarse antes de que finalizase la primera mitad del siglo XV, pero hacia 1463 (Aubrun 1951, pp.V-VII) otro copista, menos escrupuloso y fiel, de forma consciente ha modificado el texto de su modelo $\mathbf{z}$ sometiéndolo a otro de los modos del tratamiento de la materia textual distinto del empleado en $\mathbf{M}$ y $\mathbf{z}$, a saber, el de la abbreviatio, el de la supresión de la bimembración con la consiguiente eliminación de los latinismos o su sustitución por vocablos o perífrasis romances. El resultado de esta intervención simplificadora operada por el copista de $\mathbf{H}$ ha producido un texto, como acertadamente indica María Morrás (2010, pp.225-226),

de un estilo más cercano a las características propias del castellano, más elegante y comprensible, que, siendo como es posterior a $\mathbf{M}$, muestra una evolución hacia una mayor naturalidad en los usos lingüísticos, que abandonan el exceso latinizante, fruto de un cierto complejo de inferioridad respecto al latín, propio de las primeras décadas del siglo XV. 
Esta personalísima intervención del copista de $\mathbf{H}$ lo aleja de $\mathbf{z}$ y también de $\mathbf{M}$, pero, a pesar de las modificaciones en él operadas, sigue conservando lecturas auténticas de $\mathbf{z}$, que nos permiten sostener que $\mathbf{M}$ y $\mathbf{z}$ procedían ciertamente de $\mathbf{X}$ pero de forma independiente entre sí, configurando cada uno de ellos una rama propia de la tradición manuscrita. Si, en efecto, $\mathbf{M}$ es más fiel al arquetipo conservando aproximadamente más de tres cuartos de las buenas lecturas de éste, en $\mathbf{H}$ todavía se conservan algunas buenas lecturas de $\mathbf{z}$, que han sido innovadas o erróneamente interpretadas por M. Como podrá comprobarse por la lectura del aparato crítico con la que hemos dotado nuestra edición, son varias las omisiones de $\mathbf{H}$ y muchos los errores cometidos por su copista, pero $\mathbf{M}$ no se libra tampoco de una clarísima omisión que encontramos en el capítulo 10, en el que el original latino nos transmite esta lectura: si quid in uobis romani spiritus est, que $\mathbf{M}$, sin traducir spiritus y dejando un espacio en blanco, interpreta de esta menera: «si en vosotros ay alguna parte del romano», mientras que $\mathbf{H}$ nos muestra la lección correcta: «si en vosotros ay alguna parte del romano bien e alto e esforçado coraçón». Además, hay un buen número de lecturas en las que $\mathbf{H}$ conserva la buena lectura que tenía $\mathbf{z}$ frente a una innovación de $\mathbf{M}$, que la aleja de $\mathbf{X}$. Los ejemplos más claros son los siguientes: cama $\mathbf{H}$ (lat.: lecto): cámara $\mathbf{M}$; vedaron $\mathbf{H}$ (lat.:uetant) : estrañan $\mathbf{M}$; al adultero $\mathbf{H}$ (lat.: adultero) : al adulterio $\mathbf{M}$; çelar $\mathbf{H}$ (lat.: celare) : ençelar $\mathbf{M}$; de tu morada $\mathbf{H}$ (lat.: domus) : de tus moradas $\mathbf{M}$; adultero $\mathbf{H}$ (lat.: adultero) : adulterio $\mathbf{M}$; gloria o nonbre de incorruptible castidat $\mathbf{H}$ (lat.: incorruptibilis gloria pudicitie): gloria e incorruptible castidat $\mathbf{M}$; diste paçiençia $\mathbf{H}$ (lat.: patientiam prebuisti) : desta paçiençia $\mathbf{M}$; el anima $\mathbf{H}$ (lat.: anima) : el animo M, etc. El estema que proponemos es el siguiente:

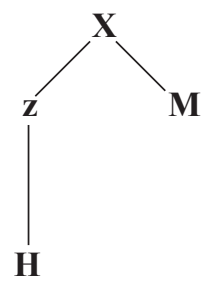

Respecto al original latino que sirvió de base a la traducción castellana, nos habíamos inclinado, en un principio, por seguir la edición de Jan Follak (2002, pp.209211) eligiendo de acuerdo con el texto castellano las variantes que allí aparecen de los testimonios T J Ma y E. Pero finalmente nos hemos inclinado por transcribir el texto real y concreto que nos ofrece el manuscrito ${ }^{13}$ del Archivo de la Corona de Aragón, Cod. Casa Real 4(Curiosa 7), ff. 119 $-120^{\mathrm{r}}(=\mathbf{C u})$, que hemos cotejado con la citada edición y las variantes de los manuscritos allí utilizados. Algunas lecturas, no muchas, de $\mathbf{C u}$, que no concuerdan con el texto castellano, han sido sustituidas por otras que

\footnotetext{
${ }^{13}$ Agradecemos a Jorge Fernández López, Catedrático de Filología Latina de la Universidad de la Rioja, el habernos facilitado información de trabajo de María Morrás cuando ya teníamos lista esta edición y proporcionado copia digitalizada del manuscrito $\mathbf{C u}$.
} 
nos ofrecen los citados testimonios y edición, pero hay otros muchos casos en los que $\mathbf{C u}$, a nuestro entender, nos ofrece una lectura más cercana al romance que las de todos ellos y esa es la que mantenemos. Teniendo siempre en cuenta el texto castellano, hemos secluido entre corchetes \{\} dos pasajes latinos a los que hicimos referencia anteriormente y hemos conjeturado que el manuscrito que sirvió de base a la traducción castellana debía de presentar (praefatio) coacta en vez de cognita o cognitam de los manuscritos, y que incluyese (capítulo 10) después de infixis, lectura de $\mathbf{C u}$, el término manibus, de acuerdo con la traducción 'poniendo sus manos', y finalmente (capítulo 11), que en vez de incorrupte et inmaculate trajese la lectura corrupte et maculate.

Como hipotético texto latino subyacente a la traducción castellana, nos basamos en un texto concreto, el ms. del Archivo de la Corona de Aragón, Cod. Casa Real 4 (Curiosa 7), ff. $119^{\mathrm{r}}-120^{\mathrm{r}}(=\mathbf{C u})$, confrontado con los testimonios que nos ofrece la edición de Jan Follak (=codd.), a saber: Todi, Biblioteca Comunale, ms. 53, ff. 49r-49v (=T); Chicago, Newberry Library, ms. 93.6, ff. 143-148 (=J); Greifswald, Universitätsbibliothek, ms. Lat. Fol.15, ff. 17-19 (=Ma); Aeneas Silvio Piccolomini, Epistulae, Mailand: Lurich Scinzenzeler, 1496, Ep.427 (=E). El texto castellano ha sido establecido sobre estos dos manuscritos: Madrid, Biblioteca Nacional, ms. Vitr. 17-4, ff. $89^{\mathrm{r}}-93^{\mathrm{r}}(=\mathbf{M})$; Londres, British Library, ms. Add. 33.383, ff. $\left.2^{\mathrm{r}}-5^{\mathrm{r}}(=\mathbf{H})\right]$

\section{/f.119r/Declamatio Colutii preclari cançelari florentini circa Lucreciam.}

\section{PRAEFATIO}

Lucretia Spurii Lucrecii filia et Collatini Tarquini uxor a Sexto Tarquino regis Tarquini filio per uim coacta ${ }^{14}$ ipsa consentiente solum infamie metu, ne Tarquinus sicut minabatur sibi occise iugulaturum seruum in lecto sociaret. Vocatis ad se patre et uiro eis ${ }^{15}$ rem narrat, ultionem iniurie promitti facit et demum uult se ocidere; uetant pater et coniunx.

\section{$<$ PROHEMIO $>$}

/f.89r/ Lucreçia, fija de Espurio Lucreçio e muger ${ }^{16}$ de Colatino Tarquino, forçada por $^{17}$ Sexto Tarquino, fijo del Rey Tarquino, dando ella logar contra su voluntad a la fuerça solo por temor de la infamia ${ }^{18}$, por quanto Tarquino ${ }^{19}$ segund amenazava

\footnotetext{
14 coacta nos: cognita(m) codd.

15 eis Cu: om. codd.

16 e muger $\mathbf{M}$ : muger $\mathbf{H}$

17 forçada por $\mathbf{H}$ : forçada de $\mathbf{M}$

18 de la infamia $\mathbf{M}$ : de infamia $\mathbf{H}$

19 Tarquino-----en la camara M: Tarquino menazava de echar un sclavo suyo degollado en la propia cama della $\mathbf{H}$
} 
dixo ${ }^{20}$ que degollaría un esclavo e lo pornía con ella de consuno en la cama ${ }^{21}$, llamó $^{22}$ al padre e a su marido, e contóles ${ }^{23}$ el fecho ${ }^{24}$ e fizo con ellos que le prometies$s^{25}{ }^{25}$ vengança d'él, e después ella ${ }^{26}$, queriéndose matar, el padre e el marido gelo vedaron ${ }^{27}$ segúnd se contiene en lo infrascripto. ${ }^{28}$

(1)Noli te afflictare Lucretia; satis ut ${ }^{29}$ maximum argumentum dedisti te adultero non consensisse tibique uim illatam. Quam penam ${ }^{30}$ eius expectas, que ultro quod celare poteras acuses?

(1) $\mathrm{O}^{31}$ mi Lucreçia, non te quieras afligir ${ }^{32}$ nin atribular por el desastrado caso avenido, ${ }^{33}$ ca bien $^{34}$ es grande e asaz provado argumento el que de ti has dado e de tu continente ${ }^{35} \mathrm{vida}$, por el qual de manifiesto ${ }^{36}$ paresçe tu ${ }^{37}$ non aver consentido de tu voluntad al adúltero, ${ }^{38}$ mas que te ${ }^{39}$ fue por él fecha desmesurada fuerça. Pues ipor qué quieres o esperas que te sea dada pena de aqueste fecho más de la que mesma te das tú, que, podiéndolo çelar ${ }^{40}$ e tener ${ }^{41}$ en occulto, de tu propia voluntad lo acusas?

(2) Hoc adiuvat uita precedens tua, que non solum in hominum oculis sed in secretis domus penetralibus frugalitatem et pudicitiam coluisti. An recolis, mea Lucretia, cum paucis ante diebus una cum improbo illo adultero prima facie huc aduenimus, tu inter seruas lanifitio intenta reperta es, improuisa, incauta, nec uirum nec hospitem ${ }^{42}$ tunc expectans; ea dies, illa deprensio castitatis tibi uictoriam dedit. Regis nurus et filias commenssationibus occupatas inuenimus; tu illis prelata es, tibi incorruptibilis gloria pudicitie parta est.

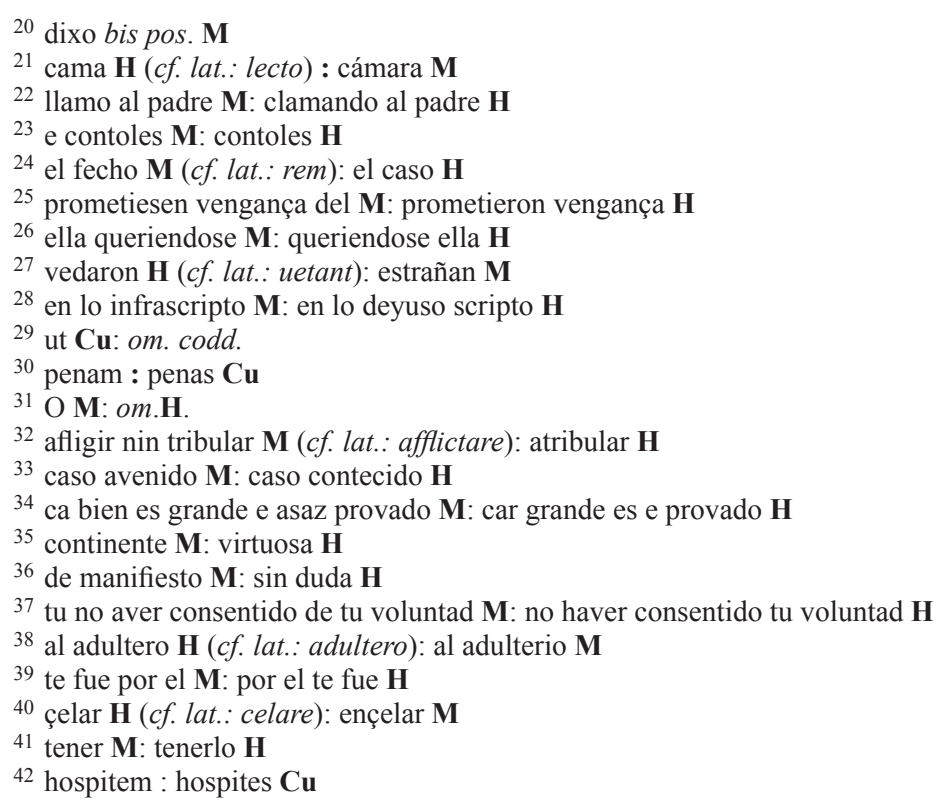


(2) Quanto más que a te salvar e fazer sin culpa del tal error, ayuda mucho ${ }^{43}$ la preçediente $^{44}$ linpia $^{45}$ e clara vida tuya. Ca non solamente en vista ${ }^{46}$ e aspecto de los onbres, mas en los secretos lugares de tu morada, ${ }^{47}$ siempre guardaste e onrraste la castidat e lo que a dona ${ }^{48}$ digna de todo loor e al honor e estado ${ }^{49}$ de tu marido e de tu casa fue conplidero e conveniente. E entre las otras cosas que dan testimonio ${ }^{50} \mathrm{de}$ tu casta mente se te deve recordar de cómmo pocos días antes del infortunado caso venimos de consuno ${ }^{51}$ con el malvado e perverso adultero ${ }^{52} / \mathrm{f} .89 \mathrm{v} / \sin$ tu ser sabidora de nuestra venida, e te fallamos a desora en honesto aparato, que estavas con tus sirvientes e servidoras intenta ${ }^{53}$ en los offiçios domésticos, sin esperar tú por aquel día a tu marido nin a otro huésped alguno. Deves, pues, considerar que aquella ora e aquel exerçiçio e occupaçión en que te assí ${ }^{54}$ fallamos, e acto de castidat, te dio victoria del perpetrado ${ }^{55}$ delicto. Ca las otras nueras e fijas del rey, todas las ovimos fallado dándose a deleytes e otros deportes e comensaçiones. ${ }^{56}$ Assí que bien paresçe ${ }^{57}$ e se esmeró por entonçe tu preheminençia en virtudes ${ }^{58}$ sobre todas ellas, por la qual, por tus virtuosas condiçiones, tienes adquirida gloria ${ }^{59}$ e nombre de incorruptible castidat.

(3) Nos iniuriam ulciscemur, que mesta uiolentos compressus improbi iunenis pertulisti, ${ }^{60}$ dum ille mala gaudia ex inuita capiebat. Videbis leta meritum regia de prole supplicium. Cur quod ${ }^{61}$ coacta prebuisti sibi de libidine nephanda solatium, tua morte tuoque cruore uis ferocem eius animum saciare? An tibi non satis nota crudelitas patris, immanitas filiorum? Iste corruptor corporis tui, quot cedes expleuit in Gabios, quot ibi circumuenit innocentes?; si ipsum odis, si sibi ex animo supplicium optas, fac uiuas; fac quod te uideat in suis penis exultare; fac quod cum se uiderit inuisum et infamem periturum, te cuius corpus attigit, uideat integro fame

\footnotetext{
43 mucho $\mathbf{M}$ : del todo $\mathbf{H}$

${ }^{4}$ la preçediente $\mathbf{M}$ (cf. lat.: precedens): la pasada $\mathbf{H}$

45 limpia e clara $\mathbf{M}$ : clara e limpia $\mathbf{H}$

46 en vista e aspecto de los onbres $\mathbf{M}$ (cf. lat.: in hominum oculis): en vista de la gente $\mathbf{H}$

${ }^{47}$ de tu morada $\mathbf{H}$ (cf. lat.: domus): de tus moradas $\mathbf{M}$ et Morrás

48 dona $\mathbf{M}$ :muger $\mathbf{H}$ et Morrás

49 e estado de tu marido e de tu casa fue conplidero e conveniente $\mathbf{M}$ : y estado de tu marido complia $\mathbf{H}$

50 testimonio de tu casta mente $\mathbf{M}$ : testimonio de tus costumbres o voluntat $\mathbf{H}$ testimonio de tú castamente Morrás

51 de consuno $\mathbf{M}$ : en companya $\mathbf{H}$

52 adultero $\mathbf{H}$ (cf. lat.: adultero): adulterio $\mathbf{M}$ et Morrás

53 intenta en los offiçios domesticos M (cf. lat.: lanifitio intenta): afazendada en las necesidades de tu casa $H$

54 assi M H : allí Morrás

55 del perpetrado $\mathbf{M}$ : de desastrado $\mathbf{H}$

56 comensaçiones $\mathbf{M}$ (cf. lat.: commenssationibus): conversaçiones $\mathbf{H}$ et Morrás

57 paresçe e se esmero $\mathbf{M}$ : paresçe ese smero $\mathbf{H}$

58 en virtudes $\mathbf{M}$ : en virtut $\mathbf{H}$

59 gloria o nonbre de incorruptible castidat $\mathbf{H}$ (cf. lat.: incorruptibilis gloria pudicitie): gloria e incorruptible castidat $\mathbf{M}$ et Morrás

60 pertulisti Cu: contulisti codd.

61 quod Cu: que codd.
} 
lumine superesse. Noli, Lucretia, uiduare coniugem, orbare patrem ${ }^{62}$ et filiis matrem auferre: opta uitam ut aspicias aliquando uindictam.

(3) Demás d'esto sé cierta que nós vengaremos la iniuria, ${ }^{63}$ e que tú, la qual llorosa e triste padeçiste los violentos e forçados tocamientos del perverso ioven ${ }^{64}$ quando él de la forçada se gozava en malo e dañado gozo e delectaçión, verás leda ${ }^{65}$ e gozosa la devida vengança que se fará en el linaje real. Pues ipor qué quieres tú, que costreñida e por fuerça le diste solaz ${ }^{66}$ de tan neffanda ${ }^{67}$ luxuria, fartar con tu muerte ${ }^{68}$ e con tu sangre el su feroz ${ }^{69}$ e fiero ánimo? ¿Por ventura non te es asaz conosçida la crueldat de su padre e la inhumanidat de sus fijos? Ca este corruptor de tu cuerpo, sabido es quántas muertes fizo e cometió en los Galios ${ }^{70}$ e quántas personas innoçentes aviltóo ${ }^{71} \mathrm{e}$ deturpó antes que a ti llegasse. Assí que, si lo aborresçes e tienes en odio, e si con todo ánimo desseas vengança e tormento ver d'él, faz que bivas e que te vea él ser alegre e gozarte $^{72}$ en sus penas, e que quando él se verá en su condenaçión, e que le converná peresçer ${ }^{73}$ e sentir açerbos e graves tormentos, $/ 90^{\mathrm{r}} /$ vea él a ti, cuyo cuerpo forçó, resplandeçer por claror e entera lunbre de linpia e clara fama. E non quieras, o Lucreçia, ${ }^{74}$ viduar $^{75}$ a tu marido, nin privarte ${ }^{76}$ a tu padre, nin orfanar ${ }^{77}$ a tus fijos: dessea la vida porque veas la vindita. ${ }^{78}$

(4) Non habes unde mori uelle debeas; polutum est corpus, sed integer animus. Nulla culpa sine consensu contrahitur. Quis nescit te non potuisse resistere nudam, dormientem, incautam et nichil tale uerentem, armato iuneni ad homicidium uel adulterium preparato? Potuit illa etate florida e $t^{79}$ auctoritate regia quamlibet aliam permulcere et secum in illecebras trahere, rigidum uero pectus tuum molire non potuit. Solus ille cum duo tantum essetis, uiolentiam intulit et in corpus tuum adulterium patrauit atque perfecit. Tu, quomodo ${ }^{80}$ quod muliebris fragilitas est, iniuriam pertulisti, sed mentem intra concubitus uiolentiam pudicissimam conseruasti. Si

\footnotetext{
62 patrem $\mathbf{C u}$ : parente codd.

63 la iniuria $\mathbf{M}$ (cf. lat.: iniuriam): la injuria tuya nuestra $\mathbf{H}$

64 iouen M H: omne M secundum Morrás (perperam)

65 leda $\mathbf{M}$ (cf. lat.: leta): alegre $\mathbf{H}$

${ }^{66}$ solaz de $\tan \mathbf{H}$ (cf.lat.: de... solatium): solaz e $\mathbf{M}$

${ }^{67}$ neffanda luxuria $\mathbf{M}$ ( $c$ f. lat.: libidine nephanda): negado peccado $\mathbf{H}$

68 con tu muerte e con tu sangre $\mathbf{M}$ (cf. lat.: tua morte tuoque cruore): con tu muerte e sangre $\mathbf{H}$

69 el su feroz e fiero animo M (cf. lat.: ferocem eius animum): el su fiero e malvado animo $\mathbf{H}$

${ }^{70}$ Galios $\mathbf{H}$ (cf. lat.: Gabios): italos $\mathbf{M}$ ante corr. Galios $\mathbf{M}$ post corr.

71 avilto e deturpo $\mathbf{M}$ : avilto e desonro $\mathbf{H}$

72 gozarte $\mathbf{M}$ : gozar $\mathbf{L}$

73 le converna peresçer $\mathbf{M}$ (cf. lat.: periturum): le converna padesçer $\mathbf{H}$

74 o Lucreçia M (cf. lat.: Lucretia): o mi Lucreçia $\mathbf{H}$

75 viduar $\mathbf{M}$ (cf. lat.: uiduare): enviudar $\mathbf{H}$

${ }^{76}$ ni privarte a tu padre $\mathbf{M}$ : nin privar a ti de tu padre $\mathbf{H}$ nin privar a tu padre Morrás

77 orfanar $\mathbf{M}$ : huerfanar $\mathbf{H}$

78 vindita $\mathbf{M}$ (cf. lat.: uindictam): vengança $\mathbf{H}$

79 et auctoritate regia : auctoritatis regia $\mathbf{C u}$

80 quomodo $\mathbf{C u}$ : om. codd.
} 
gloriam queris, nichil huic glorie potes addicere que iuneni amanti et auido, libidinem suam inexplent, $i^{81}$ te non mulierem carneam sed statuam marmoream prebuisti. Adde, ${ }^{82}$ cara Lucretia, quod tu non mortem illo uiolento consensu sed infamiam effugere uoluisti. Tunc $/ f .119^{v /}$ enim demum patientiam prebuisti tyranno, cum tibi iugulande seruum nudum occisurum se iuxta corpus tuum minatus est.

(4) Non tienes razón por que devas querer morir, ca si tu cuerpo fue ensuziado, ${ }^{83} \mathrm{el}$ ánimo quedó entero ${ }^{84}$ e neto: ninguna culpa se puede incurrir sin consintimiento. ¿Quién será aquel que non dubde tú non poder resistir estando nuda, durmiendo, descuydada e sin temor de tal cosa, al mançebo armado e que estava ya de todo punto offresçido e dispuesto al homiçidio ${ }^{85} \mathrm{o}$ al adulterio? Pudiera él, segund su floresçiente edat e segund su real auctoridat, comover e atraer con mansas, laçivas ${ }^{86}$ e dulçes palavras a otra qualquier fenbra ${ }^{87}$ en venéreos ${ }^{88}$ actos e corpóreas delectaçiones consigo, enpero non pudo ablandar el rezio, fuerte, casto ${ }^{89}$ e continente pecho tuyo, e en caso que anbos érades solos, non por tu voluntat, mas por fuerça ${ }^{90}$ e violençia, perpetró, ${ }^{91}$ cometió e acabó el adulterio en tu cuerpo, e tú, segúnd ${ }^{92}$ lo padesçe la feminina flaqueza, sofriste la iniuria, mas guardaste ${ }^{93}$ incorruptíssimo e muy casto el tu generoso ánimo. Por tanto, si tú desseas ${ }^{94} \mathrm{o}$ buscas gloria, non la puedes aver mayor que la que has avido en aqueste fecho, ${ }^{95}$ tú, que al mançebo amante ${ }^{96}$ e ençendido en luxuria, cunpliendo su desordenado ${ }^{97}$ fervor, padeçiste non commo muger carnal, mas commo una estatua ${ }^{98}$ marmórea. Piensa e añade más a tu loor, o muy clara Lucreçia, que por el tal violento ${ }^{99}$ consentimiento non quesiste fuyr la muerte, mas $/ 90^{\mathrm{v}} /$ la infamia, e assí mesmo, diste ${ }^{100}$ paçiençia, al tirano que te amenazava de muerte e que pornía muerto açerca de ti, en tu tálamo e cama, al esclavo.

\footnotetext{
81 inexplenti $\mathbf{C u}$ : explenti codd.

${ }^{82}$ Adde : Age $\mathbf{C u}$

83 ensuziado $\mathbf{H}$ (cf. lat.: polutum): deturpado $\mathbf{M}$

84 entero e neto $\mathbf{M}$ : entero $\mathbf{H}$

85 al homicidio o al adulterio $\mathbf{M}$ : al homicidio o adulterio $\mathbf{H}$

${ }^{86}$ laçivas $\mathbf{M}$ : om. $\mathbf{H}$

87 fenbra $\mathbf{M}$ : duenya $\mathbf{H}$

88 en venereos e corporeas delectaçiones consigo $\mathbf{M}$ : en semejantes actos quales tu a el negaste $\mathbf{H}$ en venéreo actos e corpóreas delectaçiones consigo Morrás

${ }^{89}$ casto e continente $\mathbf{M}$ (cf. lat.: rigidum): casto $\mathbf{H}$

${ }^{90}$ por fuerça e violencia $\mathbf{M}$ (cf. lat.: uiolentiam): por fuerça e temor de desonra $\mathbf{H}$

91 perpetro $\mathbf{M}$ : om. $\mathbf{H}$

92 segund lo padesçe la femenina flaqueza $\mathbf{M}$ (cf. lat.: quod muliebris fragilitas est): segunt paresçe $\mathbf{H}$

93 guardaste incorruptissimo e muy casto el tu generoso animo M (cf. lat.: mentem...pudicissimam conseruasti): guardaste de corroper el muy casto e generoso animo tuyo $\mathbf{H}$

94 desseas o buscas $\mathbf{M}$ : desseas e buscas $\mathbf{H}$

95 en aqueste fecho $\mathbf{M}$ : om. $\mathbf{H}$

96 amante e ençendido en luxuria $\mathbf{M}$ (cf. lat.: amanti et auido): amante ençendido $\mathbf{H}$

${ }^{97}$ su desordenado fervor $\mathbf{M}$ (cf. lat.: libidinem suam): su desordenado e mal deseo $\mathbf{H}$

98 estatua marmorea M (cf. lat.: statuam marmoream): statua de piedra marmol $\mathbf{H}$

99 violento consentimiento $\mathbf{M}$ ( $c$ f. lat.: uiolento consensu): forçado consentimiento $\mathbf{H}$

100 diste paçiençia $\mathbf{H}$ (cf. lat.: patientiam prebuisti): desta paçiençia $\mathbf{M}$
} 
(5) Te pater, te uir culpa absoluunt; \{noli sola te ipsam qua uacas culpa damnare\}. Infamiam ascita morte fugimus, tu famam corrumpis; tristitiam uite morte nobis illata finimus, tu uindicte gaudia mortem properans non expectas; denique scelus aliquod, dum nobis manus inicimus, expiamus, tu innocentiam occupata morte corruptura es. Vir, pater, Brutus et alii coniuncti, qui te culpa absoluunt, ne te occidas uetant: cur te occidendo iuditium ipsorum dampnas? Si te occidis, culpam tibi, qua cares quamue fugis, incurris. Nunquam putabitur innocens, qui se nocentem supplitio afficit.

Altera $^{101}$ pars declamationis, uidelicet Lucretie responsio.

(5) Mira, pues, que tu padre e tu marido te absuelven de la culpa, e cata que todos fuýmos la infamia de la çierta e sabida muerte; no quieras, en te matando, corronper tu fama, ca non has por saber que las personas fenesçen en la muerte la tristeza de la vida, e tú quieres fazer lo contrario, ca en te llegando a la muerte, fuyes el gozo e plazer de la devida vengança; demás d'esto, deves considerar en cómmo las personas que ponen en sí crueles manos, cometen ${ }^{102}$ enorme delicto. Pues ¿quieres tú agora corronper tu inoçençia occupándote ${ }^{103}$ en muerte? Tu marido ${ }^{104}$ e $\{\mathrm{el}\}$ padre, Bruto e tus propincos, los quales todos te absuelven de la culpa, te vedan ${ }^{105}$ la muerte, pues ¿por qué quieres tú, ${ }^{106}$ matando a ti mesma, dañar e despreçiar el iuyzio de aquéllos? Si te matas, piensa cómmo incurres en la culpa de que caresçes ${ }^{107}$ la qual por tu muerte non fuyes, ${ }^{108}$ ca nunca se pensará ser inoçente la persona que por sí mesma ${ }^{109}$ se dio la pena e tormento meresçido por los culpados.

Síguesse la otra parte ${ }^{110}$ de la declamaçión, conviene saber la de Lucreçia en contrario.

(6) Nolite me, pater sanctissime, tuque luce quondam mihi carior coniunx, mortem 111 prohibere; nisi me occidero, nunquam fides erit me potius infamiam uitare uoluisse quam mortem. Quis unquam crederet quod ille me seruicidio terruerit meque magis consotiandi serui ignominiam suspitiosam timuisse quam mortem, nisi moriendi fortitudine audatiaque probauero? Restabit me miseram turpissima ${ }^{112}$ labes infamie

\footnotetext{
101 Altera pars declamationis, uidelicet Lucretie responsio $\mathbf{J}:$ om. $\mathbf{C u}$

102 cometen $\mathbf{H}$ : que cometen $\mathbf{M}$

103 ocupandote en muerte $\mathbf{M}$ (cf. lat.: occupata morte): dandote la muerte $\mathbf{H}$

104 tu marido e $\{\mathrm{el}\}$ padre, Bruto e tus propincos $\mathbf{M}$ (cf. lat.: Vir, pater, Brutus et alii coniuncti): tu marido e padre e tus mas propinquos parientes $\mathbf{H}$

105 vedan $\mathbf{H}$ (cf. lat.: uetant): estrañan $\mathbf{M}$

106 tu M: om. H

107 de que caresçes $\mathbf{M}$ (cf. lat.: qua cares): que no tienes $\mathbf{H}$

108 fuyes $\mathbf{H}$ : fuys $\mathbf{M}$

109 por sí mesma se dio la pena e tormento meresçido por los culpados $\mathbf{M}$ (cf. lat.: se nocentem supplitio afficit): por si mesma a la pena e tormento de los culpados se consiente $\mathbf{H}$

110 la otra parte de $\mathbf{M}$ (cf. lat.: altera pars): om. $\mathbf{H}$

111 mortem Cu: morte codd.

112 turpissima : turpissimam $\mathbf{C u}$
} 
Lucretiam potius adulteram uoluisse uinere quam pudicam mori. Nonne uidetis quod me non uite uultis sed infamie reseruare?

(6) O mi buen padre, ${ }^{113}$ e tú, mi marido a mí más caro que la luz del día, ${ }^{114}$ non querades ${ }^{115}$ deffenderme la muerte, la qual si yo non me diere, non se creerá iamás que yo quisiesse antes ${ }^{116}$ evitar e fuyr la infamia que la muerte. ¿Quién será aquel que crea quél adulterante ${ }^{117}$ me pusiesse temor con la /91r/ muerte del esclavo, e que la tanta e tan iniuriosa ${ }^{118}$ infamia de que yo fuy atemorada de orrible compañía yo la oviesse temido más que la muerte? Lo qual yo provaré e confirmaré con la denodada manu executiva ${ }^{119}$ en mí mesma; lo qual si yo non fago, restará en mí, mesquina, perpetua ${ }^{120}$ e muy turpe manzilla de infamia, e dirán las gentes: «más quiso Lucreçia bevir adúltera que morir casta». E non consideraes de cómmo non me queredes guardar ${ }^{121}$ para vida, mas para infamia.

(7) Consulite quod promisistis iniurie, sancite matrimoniales toros, facite quod ultio tanti flagitii securos reddat aliarum somnos. Si negligentius hoc egeritis, uagabitur effrenis libido, et nedum uiris absentibus, sed in maritorum complexibus romane mulieres proteruorum iunenum uiolentia comprimentur. ${ }^{122}$ Et enim que mulier tuta erit, uiolata Lucretia?

(7) Tractad, ${ }^{123}$ pues, e aved ${ }^{124}$ vuestro conseio çerca de la promessa que me $e^{125}$ avedes fecho en razón de la devida vengança de una tan enorme iniuria, ${ }^{126}$ e fortifficat ${ }^{127}$ los tálamos matrimoniales: faziendo por manera que en vengándose un $\tan _{\text {açerbo }}{ }^{128} \mathrm{e}$ tan grave crimen, su vengança faga ${ }^{129}$ seguros los tálamos de las otras donas, e dexadme a

\footnotetext{
$113 \mathrm{O}$ mi buen padre e tu mi marido $\mathbf{M}$ : Mi buen padre e tu mi señor e marido $\mathbf{H}$

114 del dia M: om. $\mathbf{H}$

115 querades $\mathbf{M}$ : querays $\mathbf{H}$

116 antes evitar e fuyr $\mathbf{M}$ (cf. lat.: potius...uitare): scusar e fuyr $\mathbf{H}$

117 quel adulterante $\mathbf{M}$ : que aquel malvado $\mathbf{H}$

118 iniuriosa $\mathbf{M ~ H}$ : invidiosa Morrás

119 executiva $\mathbf{M}$ : essecutora $\mathbf{H}$

120 perpetua e muy turpe manzilla de infamia $\mathbf{M}$ (cf. lat.: turpissima laves infamie): perpetua e muy fea manzilla $\mathbf{H}$ perpetua e muy turpe manzilla e infamia Morrás

121 guardar M H : quedar M secundum Morrás (perperam)

122 comprimentur : comprimetur $\mathbf{C u}$

123 Tractad----vengança M (cf. lat.: Consulite quod promisistis iniurie): Tratat pues et seguratme de la proferida vengança $\mathbf{H}$

124 e aved M : e aviendo Morrás

125 me M: om. Morrás

126 iniuria M H : infamia Morrás

127 e fortifficat los talamos matrimoniales $\mathbf{M}$ (cf. lat.: sancite matrimoniales thoros): e reparat la lision fecha a mi matrimonio $\mathbf{H}$ e fortificar los tálamos matrimoniales Morrás

${ }^{128}$ un tan açerbo e tan grave crimen $\mathbf{M}$ (cf. lat.: tanti flagitii) : un grave e feo acometimiento $\mathbf{H}$

129 faga seguros los talamos de las otras donas M (cf. lat.: securos redat aliarum sompnos): faga seguros los casamientos de las otras Romanas $\mathbf{H}$
} 
mí fazer sacrifiçio ${ }^{130}$ de mi persona. E pensad que, si un tal error será ${ }^{131}$ punido negligentemente, que vagará ${ }^{132}$ e se tenderá la desenfrenada luxuria, ${ }^{133}$ non solamente en absençia de los maridos, mas en ${ }^{134}$ los braços d'ellos, e en menospreçio del fe de rey ${ }^{135}$ e fe conyugal serán ofensadas ${ }^{136}$ las dueñas Romanas por violençia ${ }^{137}$ de los dissolutos mançebos; ca pensar devéys ${ }^{138}$ quál muger será segura seyendo forçada Lucreçia.

(8) Tu autem, carissime coniunx, quomodo poteris in meos ire complexus qui te non uxorem tenere tuam, sed scortum Tarquini recorderis?; et tu, pater sanctissime, quomodo me tuam filiam appellabis, que pudititiam quam sub optima disciplina tua ab infantia didici, tam infeliciter amisi, tamque iniuriose corrupi? Me miseram!, audebone natos intueri meos quorum uentrem adulter oppresit ${ }^{139}$ ? Quid, si semem infaustum uisceribus inhesit meis?, an expectabo donec ex adulterio ${ }^{140}$ mater fiam?

(8) E dime tú, mi muy amado marido, cómmo podrás dexarte resçebir en mis braços quando te viniere ${ }^{141}$ en menbrança que non te abraça tu muger, mas la mançeba de Tarquino. Eso mesmo ${ }^{142}$ tú, mi buen padre, cómmo me podrás llamar fija tuya, pues que la castidat que desde mi infançia, niños e tiernos años yo aprendí ${ }^{143}$ so tu muy santa paterna disçiplina, la perdí $\tan / 91^{\mathrm{v}}$ infortunadamente e con tanta iniuria la corrunpi, o mesquina de mí, ¿e osaré yo mirar a mis fijos, el seno e primera mansión de los quales amanzilló ${ }^{144} \mathrm{e}$ oprimió el adúltero?, ¿qué será si su malaventurada simiente ha quedado ${ }^{145}$ en mis entrañas?, ¿podré yo esperar $\mathrm{e}^{146}$ esperaré a que de adulterio me faga madre?

(9) Nolite iam ${ }^{147}$ michi splendorem exacte uite ante oculos ponere, /f.120r/que simul quidquid sincerum tot annis immaculatumque seruaui: infelicissima una nocte, dum accipio non hospitem sed hostem, amisi. Non est ulterius mea uita iocunda, sentio quod pudiditie studium oportunam me fecit iniurie; non formam sed castitatem meam

\footnotetext{
130 sacrifiçio de mi persona $\mathbf{M}$ : sacriffiçio de mi mesma o de mi ensuziada persona $\mathbf{H}$

131 sera punido negligentemente $\mathbf{M}$ : era punyido floxamente $\mathbf{H}$

132 vagara e se tendera $\mathbf{M}$ : vagara e se stendra $\mathbf{H}$ vagará e estendrá Morrás

133 luxuria $\mathbf{M}$ (cf. lat.: libido): suziedat $\mathbf{H}$

134 mas en $\mathbf{M}$ : mas aun en $\mathbf{H}$ et Morrás

135 del fe de rey e fe conyugal $\mathbf{M}$ : de la fe matrimonial $\mathbf{H}$

136 seran ofensadas $\mathbf{M}$ (cf. lat.: comprimentur): serán acometidas $\mathbf{H}$

137 por violencia $\mathbf{M}$ (cf. lat.: uiolentia): por forçosamiento $\mathbf{H}$

138 deveys $\mathbf{M}$ : podeys $\mathbf{H}$

139 oppresit : oppresserit $\mathbf{C u}$

140 adulterio : adultero $\mathbf{C u}$

141 quando te viniere en menbrança $\mathbf{M}$ : quando te recordare $\mathbf{H}$

142 mesmo M H: om. Morrás

143 aprendi $\mathbf{M}$ (cf. lat.: didici): prendi $\mathbf{H}$

144 amanzillo e oprimio M (cf. lat.: oppresit): amanzillo $\mathbf{H}$

145 ha quedado $\mathbf{H}$ ( $c f$. lat.: inhesit): se congelo $\mathbf{M}$

146 e M : o H

147 iam: om. $\mathbf{C u}$
} 
expugnare uoluit nefandus adulter. Si hunc fructum continentie tuli, quid polutam, strupatam et adulteram manet, nisi quod non meretrix lupanaribus ${ }^{148}$ includar, sed passim ubique diuolans ${ }^{149}$ feda prostituar?

(9) Dexad, pues, de me poner delante el esplendor de la passada vida mía, pues quanto guardé ${ }^{150}$ en puridat e linpieza sin mácula ${ }^{151}$ por tantos años, todo lo perdí en una malaventurada noche reçiviendo, ${ }^{152}$ non huésped, mas enemigo en mi casa. Sed ${ }^{153}$ çiertos que de aquí avante ${ }^{154}$ ya mi vida non puede ${ }^{155}$ alegrarse. Siento ${ }^{156}$ que el estudio $^{157}$ de la castidat me fizo oportuna de la iniuria e la causó, ca non mi forma, mas mi castidat quiso vençer e aviltar el perverso adúltero; assí ${ }^{158}$ que, si yo antes de agora mantove e guardé este fructo de continençia, ¿qué resta ya a la sin ventura de mí, estrupada, adúltera e deturpada, salvo que assí commo dissoluta fenbra sea ençerrada e reclusa en los burdeles, e que ande errando e discurriendo por las partes del mundo e abatiéndome commo persona soez e de poca valía?

(10) Hei mihi, poteritne animus iste insons et sine culpa flagitii ulterius cum hoc corrupto corpore permanere?; an putatis nullam esse uiolati corporis uoluptatem?; fatebor ocultum nefas! Parce parens, parceque marite et uos dii castarum mentium, indulgite ${ }^{159}$ offensis. Non potui, fateor, tantam animo concipere ${ }^{160}$ tristitiam nec ab illo compressu mentem adeo reuocare, quin subierint male obedientium membrorum illecebre, quin agnouerim maritalis uestigia flamme. Illa, illa tristis et ingrata licet, qualiscumque tamen uoluptas ferro ulciscenda est. Vestrum autem erit, si quid in uobis romani spiritus est, scelus illud ulcisci.Extinguatur quicquid habuit aliquod uoluptatis; nimie sunt Veneris uires. Nolo quod unquam tanti facinoris ymago ante oculos nostre mentis agatur.Nichil muliere mobilius, egritudinem animique motus nedum mollit sed extinguit tempus. Si distulero, forsan ${ }^{161}$ incipient mihi flagitiosa placere. Dimittite ferro transfigi $i^{162}$ hoc pectus, quod ille violentus amauit, in quo primum ad excitamentum libidinis infixis ${ }^{163}<$ manibus $>$ mamillas digitis contractauit suis. Nolite me etiam

\footnotetext{
148 lupanaribus : lupanarius $\mathbf{C u}$

149 diuolans $\mathbf{J}$ E: dyabolaris $\mathbf{C u}$ diuolaris T om. M

150 guarde en puridat e limpieza $\mathbf{M}$ : guarde en ninyez e limpieza $\mathbf{H}$

151 sin macula $\mathbf{M}$ : sin macula ninguna $\mathbf{H}$

152 reçibiendo $\mathbf{M} \mathbf{H}$ : recibiente Morrás

153 Sed çiertos M : e set ciertos H E sed çiertos Morrás

154 avante $\mathbf{M}$ : adelante $\mathbf{H}$

155 non puede alegrarse $\mathbf{M}$ : no me puede alegrar $\mathbf{H}$

156 Siento H: Sienta $\mathbf{M}$

157 que el studio de la castidat me fizo oportuna de la iniuria e la causo M (cf. lat.: quod pudititie studium oportunam me fecit iniurie): que el desseo de mi castedat fue ocasion de mi desaventurada injuria $\mathbf{H}$

158 assi que, si yo----soez e de poca valia $\mathbf{M}$ : om. $\mathbf{H}$

159 indulgite offensis : parcite $\mathbf{C u}$

160 concipere $\mathbf{C u}$ : concepisse codd.

161 forsan $\mathbf{C u} \mathbf{M}$ : forsitan $\mathbf{E}$ forte $\mathbf{J}$ om. $\mathbf{T}$

162 transfigi Cu: transfigam codd.

163 infixis Cu: infixas codd. [manibus add.nos]
} 
ad mei misericordiam exortari. Si uite parco, iam parcam adultere, ${ }^{164}$ si parcam adultere, ${ }^{165}$ iam parcam adultero. Si parcam adultero, iam placebit adulterium; \{iam placebit adulter\}. Inceptum est in me flagitium. Sinite morte prohibeam, ne aliquando iuuet inceptum explere: nunquam scelus permanet ${ }^{166}$ ubi incepit.

(10) ¡Ay de mí, infortunada!, ${ }^{167}$ ¿e cómmo podrá mi ánimo inoçente e sin culpa del tal error, quedar nin estar de aquí adelante con el corrompido ${ }^{168}$ e aviltado cuerpo? ¿Pensaes por ventura que sea ninguno el deleyte del corronpido cuerpo? Manifestarvos he el occulto crimen e maldat. Perdóname tú, o padre, e tú, mi señor ${ }^{169}$ e marido. E vos o dioses ${ }^{170}$ de las castas mentes, influyd ${ }^{171}$ e proffundit sobre mí la abundançia de vuestro perdón, ca vos confíesso que non puede aver $/ 92^{\mathrm{r}} /$ tanta tristeza en mi ánimo, nin por tal manera revocar mi mente ${ }^{172}$ de aquel infortunado ayuntamiento, a que non se sometiessen a él las delectaçiones de los mal obedesçientes mienbros, e a que non conosçiesse las pisadas ${ }^{173}$ de la marital flama. Aquella triste iniuria e sin grado alguno, aunque en ella fuesse qualquier deleyte, de vengar es por fierro e verdaderamente, si en vosotros ay alguna parte del romano ${ }^{174}$ bien e alto e esforçado coraçón, vuestro será vengar este crimen. Muera, muera e fenezca qualquier cosa que ovo parte alguna de delectaçión. Muchas ${ }^{175}$ e grandes son las fuerças de Venus. Non quiero yo que iamás ante los ojos de mi voluntad se presente nin parezca la ymagen de un tan enorme delicto; non ha cosa en el mundo más movible que la muger, e la deliberaçión, propósito e motivo del ánimo, non solamente lo muda ${ }^{176}$, amollesçe e ablanda el discurso del tienpo, mas tanbién los apaga ${ }^{177}$ por su discurrir. Assí que si yo dilatasse este fecho, por ventura me vernían en plazer las cosas ${ }^{178}$ enormes e los fechos e obras feas. Dexadme, pues, traspassar con la aguda ${ }^{179}$ e taiante espada aquestos mis pechos que aquel forçador amó, en los quales, para ençendimiento ${ }^{180}$

\footnotetext{
164 adultere : adultero $\mathbf{C u}$

165 adultere : adultero $\mathbf{C u}$

166 permanet $\mathrm{Cu}$ : remanet codd.

167 quedar nin estar $\mathbf{M}$ (cf. lat.: permanere): quedar $\mathbf{H}$

168 con el corronpido e aviltado cuerpo $\mathbf{M}$ (cf. lat.: cum hoc corrupto corpore): con el aviltado cuerpo $\mathbf{H}$

169 señor e marido $\mathbf{H}$ et $\mathbf{M}$ post corr.: señor marido $\mathbf{M}$ ante corr. señor marido Morrás

170 o dioses de las castas mentes $\mathbf{M}$ (cf. lat.: dii castarum mentium): o dioses de los castos pensamientos $\mathbf{H}$ dioses de las castas mentes Morrás

171 influyd e proffundit $\mathbf{M}$ : influyit $\mathbf{H}$

172 mente $\mathbf{M}$ (cf. lat.: mentem): consentimiento $\mathbf{H}$

173 las pisadas de la marital flama M (cf. lat.: maritalis uestigia flamme): las pisadas de la marital compañia H las pisadas de la marital llama Morrás

174 del romano bien e alto e esforçado coraçon $\mathbf{H}$ (cf. lat.: romani spiritus): del romano (spat.rel.)M

175 Muchas e grandes son las fuerças de Venus M (cf. lat.: Nimie sunt Veneris vires): Car aunque vosotros me perdoneys la culpa, non perdono, non perdono yo a mi la pena $\mathbf{H}$

${ }^{176}$ lo muda, amollesçe e ablanda $\mathbf{M}$ (cf. lat.: mollit): lo muda e ablandesçe $\mathbf{H}$

177 apaga por su discurrir $\mathbf{M}$ (cf. lat.: extinguit): affoga del todo $\mathbf{H}$

178 las cosas enormes e los fechos e obras feas M (cf. lat.: flagitiossa): las cosas innormes e feas $\mathbf{H}$

179 con la aguda e taiante espada $\mathbf{M}$ (cf. lat.: ferro): con la aguda espada $\mathbf{H}$

180 para ençendimiento de su luxuria M (cf. lat.: ad excitamentum libidinis): para ençendimiento de su malvado desseo $\mathbf{H}$
} 
de su luxuria, poniendo ${ }^{181}$ primeramente sus manos, sovaió ${ }^{182}$ e tractó con sus dedos mis tetas. Non me querades exhortar, ${ }^{183}$ persuader nin requerir a misericordia e piedat de mí mesma, ca si perdonasse a mi vida, perdonaría a la adúltera; e si perdonasse a la adúltera, por consiguiente perdonaría al adúltero, e si perdona/92v/sse al adúltero, seguirseýa ${ }^{184}$ plazerme el adulterio. Assí que, pues el delicto començó en mí, dexadlo ataiar por mi muerte, e que por ella mesma yo deffienda ${ }^{185}$ deverse ${ }^{186}$ continuar adelante el començado crimen, ca nunca el delicto queda donde comiença.

(11) Credant omnes me timuisse infamiam non mortem; quod testibus probare non possum, sanguine meo ratum ${ }^{187}$ efficiam. Et anima, ${ }^{188}\left\{\right.$ in $_{\text {'corrupte }}{ }^{189}$ et $\{\mathrm{im}\}$ maculate testis innocentie mee apud Minois et Radamantis ${ }^{190}$ tribunal, ibique prolem regiam uiolate pudititie ac poluti corporis accusabis, tuque, terrestre corpus, quod etiam specie tua tibi causam et occasionem adulterii peperisti, effunde animam, effunde cruorem hoc omine, ut hinc incipiat superbi regis et infauste regie stirpis ${ }^{191}$ excidium. Tuque, uir quondam carissime, tuque, pater, quorum aspectum pudore et infelicitate mea libenter effugio, uosque amici, ualete. Nec minus fortiter uindictam quam spopondistis peragite, quam ego cedem perficiam meam. Nulli romane mulieri detur in exemplum Lucretia, ut uita mea sibi persuadeant impudicis licitam fore uitam. Amen.

(11) Crean todas las gentes yo aver temido la infamia e non la muerte, lo qual, pues non puedo provar ${ }^{192}$ por testigos, yo lo faré çierto e firme por effusión ${ }^{193}$ de mi sangre. Ya tú, ${ }^{194}<$ ánima $>195$ o testigo de mi corrupta e maculata inoçençia, accusarás a mí e a la generaçión real de la quebrantada castidad e ensuziado cuerpo ant'el tribunal de Minos e Rudamanta. Tú, o terrestre cuerpo, pues por tu parescer ${ }^{196}$ pariste ${ }^{197}$ causa e

\footnotetext{
181 poniendo primeramente $\mathbf{M}$ : puso $\mathbf{H}$

182 sovaio e tractó con sus dedos mis tetas M (cf. lat.: infixas mamillas digitis contractauit suis): sobaio e tratto con aquellas mis tetas $\mathbf{H}$

183 exhortar, persuader nin requerir $\mathbf{M}$ (cf. lat.: exortari): amonestar ni requerir $\mathbf{H}$

184 seguirseya M: seguirsya $\mathbf{H}$ seguir será Morrás

185 deffienda M H: deffendí Morrás

186 deverse M H: de verse Morrás

187 ratum : latum $\mathbf{C u}$

188 anima Follak et Morrás: anime codd.

189 corrupte et maculate ( $c f$. cast. de mi corrupta et maculata)nos : incorrupte (et) immaculate codd. et $\mathbf{C u}$ corrupta, maculatae Morrás

190 Radamantis : Radamati Cu

191 stirpis Cu: prolis codd.

192 provar por testigos M (cf. lat.: testibus probare): probar por otro testigo $\mathbf{H}$

193 por effusion $\mathbf{M}$ : por derramamiento $\mathbf{H}$

194 Ya tu, o testigo----Minos e Rudamanto M: om. H

195 ánima add. nos (cf. lat.: anima): om. M H

196 por tu paresçer M (cf. lat.: specie): por tu desaventurada fermosura $\mathbf{H}$

197 pariste $\mathbf{H}$ (cf. lat.: peperisti) : diste $\mathbf{M}$
} 
occasión ${ }^{198}$ del adulterio, da ${ }^{199}$ el ánima, ${ }^{200}$ e esparze ${ }^{201}$ tu sangre en tal punto e ora, e con tal agüero ${ }^{202}$ a que desde agora comiençe destruçión, muerte e perdimiento del sobervio $^{203}$ rey e de su malaventurada ${ }^{204}$ generaçión. E tú, o mi muy amado marido, e assí mesmo tú, mi señor e padre, el acatamiento ${ }^{205}$ e vista de los quales con voluntad yo fuyo por mi pudor, ${ }^{206}$ vergüença e siniestra ventura, e vós otrosí mis amigos, bevid ledos, ${ }^{207}$ esforçándovos a la vengança ${ }^{208}$ que prometistes del perpetrado crimen, non con menos ${ }^{209}$ fortaleza que yo fenesçeré la mi vida, e non se dé exenplo a muger ${ }^{210}$ alguna Romana la vida de la sin ventura de mí $/ 93^{\mathrm{r}}$ a que ellas ${ }^{211}$ por causa mía entiendan ser líçito bevir a mugeres non castas.

Fenesçen ${ }^{212}$ las declamaçiones de Colluçio chançeller de Florençia çerca de Lucreçia.

\section{LA CARTAGINESA SOFONISBA: SU EPÍSTOLA A MASINISA Y EL RELATO DE TITO LIVIO}

Debemos a Charles Faulhaber, catedrático de Filología Románica de la Universidad de Berkeley (California) y actual director de la Biblioteca Doe de dicha institución, haber 'redescubierto' y descrito ${ }^{213}$ un interesantísimo códice en la Biblioteca Nacional de París, Ms. espagnol n ${ }^{\circ}$ 533, que contiene, además del Bursario (Saquero, e.p.) de Juan Rodríguez del Padrón, otras varias obras y, entre ellas, una Carta secreta de Sofonisba a Masinisa (folios $96^{\mathrm{r}}-99^{\mathrm{v}}$ ). Se trata de una epístola original de un autor anónimo, imitador de las Heroidas de Ovidio y posiblemente de su traductor al castellano, el mencionado Juan Rodríguez del Padrón, la cual hasta el momento, de acuerdo con la información de que disponemos, permanecía inédita. Como es bien sabido, parece haber sido el padronés Juan Rodríguez el iniciador en Castilla de las

\footnotetext{
198 causa e ocasión del adulterio M (cf. lat.: causam et occasionem adulterii): la causa destos males $\mathbf{H}$

199 da $\mathbf{M}$ : desampara $\mathbf{H}$

200 el anima H (cf. lat.: animam): el animo $\mathbf{M}$ et Morrás

201 esparze $\mathbf{M}$ (cf. lat.: effunde): desparziendo $\mathbf{H}$

202 en tal punto e ora e con tal aguero $\mathbf{M}$ (cf. lat.: hoc omine): en tal punto $\mathbf{H}$

203 sobervio M (soberbio H) : soberano Morrás

204 dela malaventurada $\mathbf{M}$ (cf. lat.: infauste): de la malvada $\mathbf{H}$

205 el acatamiento e vista $\mathbf{M}$ (cf. lat.: aspectum): el acatamiento $\mathbf{H}$

206 por mi pudor, verguença e siniestra ventura M (cf. lat.: pudore et infelicitate mea): por mi pudor e siniestra desaventura $\mathbf{H}$

207 ledos $\mathbf{M}$ : alegres $\mathbf{H}$

208 a la vengança que prometistes del perpetrado crimen M (cf. lat.: vindictam quam spopondistis): a la vengança prometida del acaesçido crimen $\mathbf{H}$

209 menos fortaleza $\mathbf{M}$ (cf. lat.: minus fortiter): menor fortaleza $\mathbf{H}$ et Morrás

210 mujer $\mathbf{H}$ ( $c$ f. lat.: mulieri): fenbra $\mathbf{M}$

211 A que ellas por causa mia entiendan ser liçito bevir a mujeres non castas $\mathbf{M}$ : en tal manera que las non castas por causa mia no hayan de creer que la vida les sea liçita $\mathbf{H}$ (Después de liçita $\mathbf{H}$ añade lo siguiente: E asi poniendo una spada por sus fermosos pechos que deyuso su negro manto tenia scondida rendio el glorioso spiritu).

${ }^{212}$ Fenesçen----çerca de Lucreçia M: om. H

${ }^{213}$ Cf. la completísima descripción de este códice en PhiloBiblon, manid 5228-XTF.
} 
cartas originales (Saquero-Gonzalez Rolán 2010, pp.52-67) en romance a imitación de la Heroidas de Ovidio, que tuvieron una gran difusión a tenor de los manuscritos que todavía conservamos, cerca de una decena, y también una cierta influencia en las literaturas peninsulares, incluyendo la vigorosa literatura catalana del siglo XV, en dos de cuyas obras señeras, Curial e Güelfa y Tirant lo Blanc, Rosa María Lida de Malkiel (1977, pp.120-123) ha encontrado no sólo ecos sino también claras reminiscencias textuales. Como señala esta admirada filóloga (Lida de Malkiel 1977, p.97), parece que la epístola literaria puesta en boca de un personaje antiguo gozó de cierta boga a mediados del siglo XV, y una prueba de ello sería, entre otras, la Declamación de Lucrecia en el Cacionero de Herberay. La epístola, que ahora editamos, se enmarca dentro del género sentimental ${ }^{214}$ y presenta, respecto a las cartas originales de Rodríguez del Padrón, la particularidad de que los personajes son realmente históricos y cuya relación amorosa transcurre a lo largo del año 203 a. C., es decir, un año antes de que termine la segunda Guerra Púnica con la victoria aplastante en Zama de los romanos sobre los cartagineses. Se podría pensar que el anónimo autor de esta epístola ha tenido como modelo literario a Ovidio (o a Juan Rodríguez del Padrón), y a Tito Livio como suministrador del tema de la relación amorosa entre Sofonisba y Masinisa, tal como Charles Faulhaber parece indicar al referirse a este historiador en dos ocasiones. Ahora bien, tras analizar con detenimiento este complejo texto, que es ciertamente una carta de amor, despecho y rabia que Sofonisba dirige a Masinisa pero también un monólogo interior y en cierta medida un diálogo in absentia con este último, podemos estar casi seguros de que Ovidio o las cartas originales del padronés han servido al autor como modelos en los que podía contemplar la forma en que una mujer enamorada como Sofonisba, que había confiado en su amante, se siente traicionada por él y le acusa de no cumplir sus promesas y de ser cobarde y pusilánime a la hora de decidir entre lo que le ordena la razón, representada por Escipión, y su propio corazón. Es por ello por lo que esta mujer toma la pluma para escribir esta carta secreta, que le servirá de venganza y denuncia contra un hombre, que había jurado y prometido cosas que resultaron ser falsas y engañosas.

Así pues, Sofonisba se nos presenta como una mujer enamorada y confiada, y tiene la desgracia de encontrarse con un hombre que sí es capaz de vencer a sus enemigos, pero, como dice ella: «una sola mujer que encomendada era a ti defender no pudiste». Así, se pone en la situación de Masinisa y afirma que actuaría de modo radicalmente distinto: «Fuera yo Masinissa y él fuera aquella que yo soy, Soffonisba, que comigo biviera y muriera, ni todas las fuerças del mundo nos despartiera». Termina la carta deseándole que tanto sus enemigos como los dioses lo traten como él lo ha hecho con ella y afirma que, de todas las maneras de muerte, debe de haber alguna más benigna que su cruel audacia y es a aquélla a la que con gusto se someterá.

El escueto resumen de la carta nos permite comprobar que el relato de Tito Livio queda muy lejos de la intención de nuestro autor o, mejor dicho, éste ha pretendido

\footnotetext{
${ }^{214}$ Sobre este género literario español comenzado precisamente por Juan Rodríguez del Padrón, hay una inmensa bibliografía y entre ella podemos citar a Antonio Cortijo Ocaña y Adelaida Cortijo Ocaña (1998, pp.63-81), Antonio Cortijo Ocaña (2001, pp.7-11; 82-83) y A. L. Baquero Escudero (1999, pp.7-16).
} 
decirnos todo lo contrario de lo que dejó escrito el gran historiador romano, para quien Masinisa es el que se enamora perdidamente, mientras Sofonisba permanece siempre distante y sólo su deseo de salvar su vida y, sobre todo, de no caer en manos de los romanos le lleva a aceptar el segundo casamiento, en vida de su primer marido, con un enemigo de su pueblo cartaginés. Que Tito Livio no está detrás de la carta se podrá comprobar por la lectura en castellano medieval de los pasajes del encuentro de Masinisa y Sofonisba, del enamoramiento del primero y del triste final de la reina, que nos ofrece uno de los ejemplares de la traducción de sus Décadas, realizada por López de Ayala, a saber, el manuscrito de la Biblioteca Nacional, ${ }^{\circ} 10.804$, ff. CCCCIIIv$\mathrm{CCCCVI}^{v}$. Si, como resulta evidente, Tito Livio en ningún momento habla de una Sofonisba enamorada, ni de una mujer despechada que termina amenazando a su amante y deseándole lo peor, podemos concluir que nuestro autor se ha debido de inspirar en otro texto sobre este mismo tema. Queda descartado Boccaccio pues, como hemos dicho, no sólo resume el relato de Tito Livio, sino que también es bastante fiel a su espíritu. Por el contrario, Petrarca se aparta, como hemos dicho, del historiador romano y convierte a Sofonisba y Masinisa en una pareja herida por la flecha del amor, que, sin embargo, ha penetrado mucho más hondo en el corazón del segundo. Es por lo tanto posible que el autor de la carta conociese el Africa del humanista italiano, y en particular dos pasajes: la larguísima ensoñación de Masinisa (vv.448-696) después de recibir de Escipión la orden de entregar la reina a los romanos, y sobre todo las palabras que pronuncia esta última una vez que el sirviente enviado por su marido le ha entregado la copa de oro que guardaba el veneno (vv.725-773), palabras con las que maldice y augura futuros males, no sólo a Escipión sino también a Masinisa; tras pronunciarlas, nos dice Petrarca ${ }^{215}$ que «luego sin pestañear bebió el fatal veneno, como si tuviese sed, y su espíritu indómito se encaminó hacia las sombras del Tártaro».

Ahora bien, ya que no nos consta que el poema Africa haya sido conocido en Castilla en la primera mitad del siglo XV, lo que podría en cierta manera invalidar la tesis de que nuestro autor se inspirase en ella, aunque muy libremente, podemos apuntar una última posibilidad, que necesitaría un análisis más detenido del que ahora podemos hacer, y es que sobre la trama conocida a través de la lectura de los capítulos citados del $A b$ urbe condita, el anónimo autor imaginase a Sofonisba como una de las heroínas ovidianas y la hiciese hablar y sentir como ellas.

\subsection{CARTA 'SECRETA’ DE SOFONISBA A MASINISA}

[París, Bibliothèque Nationale de France (Richelieu), ms. Espagnol 533, ff.96r-99v]

/f.96 ${ }^{\mathrm{r}} /<\mathrm{S}>$ olo uno de los romanos quel sinple coraçón de la desaventurada Soffonisba ama: mi cruel enemigo, o rey Masinissa, que la fe y la lealtad sobre los naçidos guardar solías, más de perpetua virtut que de fallesçibles riquezas estima ninguna

\footnotetext{
${ }^{215}$ Africa, VI, vv. 771-773: Inde malignum / ceu sitiens haurit non mota fronte venenum / tartaeasque petit violentus spiritus umbras.
} 
faziendo y de Dios inmortal el titol aperpetiendo, que señoría terrenal con alguna cobdiçia desseando, que agora de ti puedo decir: ¿ Condenaré a mí sin dexar increpar a ti?; duelo he, que la gloria en tantos años con grandes trabajos por ti aquí fiada en un breve momento por ora menguada la deves perder, ni es a mí por firme secreto tu mal penssamiento poder reparar, ca si te vergüeñas de tu mal cometido, tú solo eres bastante a ti condenar.¿Y quién más provable testigo podrá seer de tu culpa, ni a ti más digno juez podrás seyer acussado? Pues de ti solo a ti la reprenssión se esspera, me plaze en más plolongado versso de tanta injuria con esta secreta carta de ti ante ti tomar la vengança. Si alguna culpa en mi clara vida he cometido, por ti la caussa de mi pecado seyendo debía ser acussada, que sabes que ni la sobervossa fuerça de los romanos ni las dulçes profiertas ni las actraibles perssuasiones demostrantes nuevas caussas de temor, miedo y esperança no podieron; no que mi ánimo á ser jusmetido atraher, mas que de alguna paçiençia vençido en domistiqueza y fameliaridat $/ \mathrm{f} .96^{\mathrm{v}} /$ sostoviesse, antes libre sin conosçer el agravado yugo de servitut, queriendo antes la penossa muerte sof $<\mathrm{r}>$ rir que la agradable vida con cargo de catividat acreçentar. $\mathrm{Ca}$ tú solo forçador de los míos, ocupador de mis riquezas, homeçida de mi caro marido e de mis $<$ in $>$ numerables conjuntos por amistança y por debdo de sangre comigo e de otros jusmessos vasallos [h] e mantenedores, con su propia sangre y travajo del perdido estado y señoría aya con tanto amor amado que fallo seyer la culpa de un mi solo pecado, y en lugar de marido, en lugar de hermano, en remuneraçión de riquezas te reputando aya querido y en tu poder mi franco árbitro cometido; y tú <er>es perjuro por aver con la fermossura de mi pressona a mí sola y libre voluptad, la qual forçiblemente podrás posseer, pues todas las otras cossas possedías forçadas. Feziste, juraste y prometiste cossas que la lealtat ya provada del más prudente, firme y constante honbre del mundo seyendo falssas y captelossas, como agora veo, fueron; a mí fáçilment devían engañar non la de una flaca y sin corporales fuerças muger, mas como es la verdat non estimasse algo tener, pues tener no veías el mi consentimiento: ¿a qué provecho e utilidat de tu fama o plazer de ti las feziste? No creo estimes poca nin mucha gloria ser penssar corromper el ánimo virtuoso y de aquel nonbre lo desgraduar, pues la sobrada /f. $97^{\mathrm{r}}$ / presona a tu grado la podías tratar si deleite en aquella esperavas considerando el grant escargo de quien tanto te amava y de ti se fiava. Más tormento que otra cossa devieras sentir, pues ál que prolongar la pena, ál dilatar la vida, no era ya la hora tú me dexaras, que tanto dispuesta a la irrevocable muerte yo me fallava, que non amarga mas plaziente en lugar de gloriossa vengança me fuera. Oy la ora muriendo quanto yo por inmoral vida viviera, que aquello con las otras mis passadas costunbres recogiendo pusiera las plantas de los mis pies sobre los çielos, agora que lugar as dado tú, la causa seyendo, a tanto ostáculo de la mi gloria, en lo passado y en lo pressente ha dexar la vida, los inbidiossos solíçitos, escodriñadores de las cossas falssas con cara de verdat dirán: «El ánimo mío ser otro del que sienpre fue e agora se demuestra, pues dio lugar a ser corronpido y de libre que era se fizo cativo». ¿Qué diré?, ¿tomaré por parte la verdat o con mi trabajo o pena dexaré con falsso gozo a los querientes el mal ajeno alegrar? Más vale lo honesto o libre secutar que lo vituperosso y con trabajo sostener. Di, mezquina, y no fablas, pues esto tú bien sabes que vista la desfacçión de mi regno [h] privaçión de los míos quisse antes morir que servitut sostener; ¿y quién no consintirá /f.97v/ la vida quando la espantable muerte seyendo vezina menaza?, pues tú a mí dezías: «O Soffonisba, ¿qué fazes?, no quieras aquella anteçipar,- que con todo engeñosso estudio por los más sabios se deven prolongar y fazersse conviene no más 
de una vez -; con la qual toda esperança con ella fuye y es última vengança y plazer de los más [h]enemigos; con ella se amatan las iras, las enemistades en aquellos que quedan acá quando sostener la fazen e daquel que han en odio. Y tú biviendo podrás atender e ser algunt tienpo vengada de tus resçebidas injurias. Bive, pues, Sofonisba, y tú que sobrada de mí te reputas con un vençedor te conforma y iguala. Ninguna differençia será del vençido al de aquel vençedor, ca serás igual conpañera y muger en todos los días de nuestra vida a tu marido Massinissa, y no dubdes ni temas tocar la vil servitut, que antes sofrirían mis manos privar del mundo tu vida, la qual reputo igual de la mía, que mis ojos vean a ti cativa, y quando forçado te oviera de render o levar con la otra nuestra pressa ante las puertas de nuestro Capitolio, e que por los nuestros padres salientes a carrera, las honrradas matronas, deseossas maridadas y temerossas donzellas, admirables de tanto triunfo, seas vista e /f.98 $/$ pressa del pueblo romano, te prometo la no fallesçible fe de te lo manifestar e que tu propóssito puedas libremente conplir en tan breve tienpo».

Tan grandes cossas son fuidas de tu memoria; aún agora has ossado olvidar tu fe y matar tu fama, perder tu sola muger quando calladamente por que sabidora no fuesse, con las manos atadas, en son de cativa en la multitut del pueblo me feciesses levar. Di, o cruel amador, si por aquel entre los que bien amante quieres contar y sostener lo pudieras, quál dureza o inumanidad padesçer te fiziera que aquella por quien te reputavas de más amador vieras partesçipante de tan amargas lágrimas, de tan agros llantos, de tanto dolor quanto los cativos en poder estraño de sus enemigos suelen soffrir. No me clamo de la inopinada fortuna, antes me loo yo mucho della, que me ha seido begnina en aquello de lo qual yo muy descuidada me estava; por vías ocultas me ha fecho saber más de ti, a quien con falssa dredulidat mi sinple seso dio entera fe creyendo que assí commo dezías sin alguna dubda deviesse avenir y con poco acatamiento te solo escogí por el mijor de los muy buenos: ¿por qué assí mi avenimiento has defraudado, fecho falso y mentirosso? O cavalllero, que las fuerças de tus enemigos no resistir mas sobrar has ossado y las cossas a efecto con titol ajeno, tú, /f.98v/capitán seyendo, has deduzido en tu nonbre: una sola muger que comendada era a ti defender no podiste, ni por aquella los primeros golpes ossaste esperar non que de tajante espada mas de dañossas palabras enbiadas, que suelen más que ferir espantar. Y quién dubda que si a ti las menazas al tu Çipión con igual ánimo viera acatar, que mirando tu justa querella con virtuosso ánimo no dixera: «Todo lo ál sea nuestro; aya Masinissa a la Soffonisba, e pues suya ha de ser, áyala con todas las cossas a él convenientes. No sea tractada como pressa enemiga, mas como a prinçipal amiga de nuestros amigos».

O flaco [h] e sin fuerças amor en aquellos que en lo más alto de la rueda triunfan, los quales más con amor que con temor devían señorear, y desconosçidos con mucha superbia quieren el mundo amedreçer. Como a desigual poder intitulas tu nonbre en los bevientes e a quien la fortuna da el libre poder tú le privas del bien querer. Fuera yo Masinissa y él fuera aquella que yo soy, Soffonisba, que comigo biviera y muriera, ni todas las fuerças del mundo nos despartiera. Muestra tus fuerças igualando los dessiguales en tal son o manera que alguna efficaçia aya mi pobre escritura en las sordas orejas de aquel que piensso agora las tiene a mis palabras cerradas. /f.99r/E si movido por piedat recobrara sus fuerças por me salvar, si no, sienta de su pecado una tal puniçión que todos sus loores, porque en tanto el mundo ha tribulado por solo esto, se le tornen en vituperosso daño, pues manifestará non propias mas enprestadas las aver posseído. Que la virtut en esser no en paresçer consiste, lo qual no descreo que a los 
flacos es dado fazer las flaquezas, a los virtuossos ussar de prudençia, por la qual las cossas, pues se començaron, se deve en aquellas persseverar, y faziendo lo contrario son mucho más dignos de reprovar. E tú, la esperança de salvar nuestra vida, retorna en tu primero querer y mira aquello que fazes y pienssa aquello que deves, que yo soy aquella que sienpre fue y no mudo propóssito, segunt tú mudaste el loable tuyo y estás tanto firme en el abominable e, si en él continuares, ruego a las deidades de nuestros diosses que sea ésta la última vitoria que aver tú podrás de tus enemigos y en tal punto aquellos te traten que en ti ussar de más umanidat que tú contra mí demuestras querer obrar, mas no que lo fagan sino que tales sean ellos a ti qual tú eres agora a mí, que de tantas maneras de muerte alguna más begnina que tu cruel audacia en esta neçessidat me socorrerá y cunpliéndolo por mí /f.99v/ començado a tantas persecuçiones con mi propia mano daré fin.

\subsection{VERSIÓN DE TITO LIVIO SOBRE EL SUICIDIO DE SOFONISBA}

\section{[Madrid, Biblioteca Nacional, Ms. 10.804, ff.CCCCIII ${ }^{\mathrm{v}}-\mathrm{CCCCVI}^{\mathrm{v}}$ ]}

/f.CCCCIII ${ }^{\mathrm{va} /}$ E el rey Masinisa puso luego guardas a cada puerta quales cumplía por que ninguno non se fuese, e en el cavallo fue luego al palaçio del rey e tomólo. E quando el rey Masinisa entró en el alcaçar real, la mujer del rey Siphas, que era fija de Hasdrúbal, la qual avía nombre Sophonisa, vino delante d'él, e quando allí vino cató e vio al rey Masinisa entre todas las /f.CCCCIII ${ }^{\mathrm{vb} /}$ gentes que allí eran el más notable e mejor armado que ninguno, en tal ábito que paresçía rey, e luego entendió que aquel era el rey y fincó los ynojos delante d'él muy omillosamente e le dixo estas palabras: «Por çierto, los dioses otorgaron a ti e a la tu voluntad tanto poderío por que oy seamos delante ti en el estado que somos; mas si es otorgado a una cativa mujer que pueda fablar en la presençia de aquel que tiene en su poder a mi marido e mi vida, e puede inclinar los finojos en tierra e llegar a él e tocar la su mano derecha, yo te ruego e te pido e requiero por aquella real magestad que tú agora tienes, en la qual mi marido e yo estovimos non ha mucho tienpo pasado e por el nonbre e linaje e gentes de los numidianos, de la qual gente e tierra tú e mi marido el rey Siphas fustes e sodes commo de una tierra e de una naçión, e por los dioses de aqueste palaçio real que por la su graçia te quieran mejor ayudar que ayudaron a nos e te ayuden /f.CCCCIIIIra/ e te resçiban con mejor ventura que fizieron a nos en la partida, que tú quieras fazer esta graçia e esta merçet a esta tu cativa, e quieras de mí ordenar todo aquello que a tu voluntad e a tu coraçón plazerá de fazer de mí. Mas una cosa te ruego e te soplico, que tú non me quieras poner nin dexar en albedrío cruel e orgulloso señorío de ningund omne romano. Ca, por çierto, si en miente non oviese ál salvo ser mujer del rey Siphas, yo me atrevería bien a me poner e aventurar en la fe e lealtad de gente numidiana commo omnes naturales de África e aun de qualquier omne estrangero, mas tú sabes muy bien si deve dubdar el natural de Cartago de omne romano, espeçialmente yo que só fija de Hasdrúbal. Por ende te ruego e te pido merçet que si en otra menera tú me puedes delibrar, siquiera que tú me delibres por muerte. E la reyna Sophonisa, mujer del rey Siphas, era muy fermosa e moça de hedat. E quando tomó /f.CCCCIIII ${ }^{\mathrm{rb}} /$ la mano derecha del rey Masinisa suplicándole que non fuese entregada a ningund romano e otrosí oyendo las sus dulçes palabras e blandas, el coraçón del rey Masinisa fue luego 
inclinado non solamente en misericordia mas aún luxuria- e en este pecado son los numidianos comunalmente inclinados-. E d'esta manera el vençedor cayó en el lazo de la vençida e de la cativa; estonçe començó a pensar el rey Masinisa cómo e por quál manera podría él conplir lo que avía prometido a la reyna, ca él le prometió dándole su mano derecha que non la entregaría en poder de ningund romano, e pera esto pensó una cosa asaz loca e nesçia, la qual fue esta: él pensó en sí mesmo, así commo omne que estava enamorado de la reyna, de la tomar por su mujer e casar con ella, e mandó fazer un grand conbite para las bodas. E esto fazía él a fin que Sçipión nin Lelius non fallasen manera de ordenar ninguna cosa de la dicha reyna así commo prisionera después que la fallasen casda con él. Fechas /f.CCCCIIII va/ las bodas Lelius vino allí blasmando mucho d'este fecho, e fizo todo su poder por tomar a la reyna Sinphonisa e la poner con el rey Siphas su marido e con los otros presioneros para los enbiar a Sçipión; enpero finalmente el rey Masinisa le vençió con muchos ruegos que le fizo, considerando Lelius muchas ayudas que podían aver del rey Masinisa, por lo qual cobrava muchas villas y çibdades, dexóle tomar a la reyna e fincó aquel fecho así estonçe.

[El viejo Sifas es llevado como prisionero ante Escipión, quien le pregunta por qué había abandonado la amistad con los romanos y se había inclinado a firmarla con los cartagineses. A lo que aquél le contesta echando toda la culpa al embrujo e influencia que su jovencísima mujer Sofonisba había ejercido sobre él. Consciente Escipión del peligro que en el futuro representaría Sofonisba como esposa ahora de Masinisa, le exige a éste que entregue a la joven].

/f.CCCCVIrb/Quando el rey Masinisa oyó estas palabras que dixo Sçipión, toda la color se le mudó e viniéronle las lágrimas a los ojos e dixo que él estava en su poder e que le conbenía fazer su voluntad, enpero que le rogava que él quisiese remediar a la su loca promesa en quanto él pudiese, ca él avía jurado e prometido de nunca entregar a la reyna Sinphonisa en poder de ningund omne del mundo, espeçialmente de romanos, e esto dicho el rey Masinisa se fue muy turbado en su coraçón e metióse en su tienda. E después que allí llegó, mandó salir fuera a todos los que allí estavan e començó a dar muy grandes sospiros en manera que los que estavan en derredor de la tienda lo podían muy bien oýr. E faziendo esto estudo una grand ora e después dio un /f.CCCCVI ${ }^{\mathrm{va}}$ / grand sospiro e fizo llamar uno de sus siervos secretos de quien se fiava e guardava los beninos e las poçoñas que los reys en aquel tienpo acostunbravan de traer para la que tomase aquella poçoña e fiziese d'él un bebraje e lo levase a lareyna Sinfonisa e le dixiese que lo beviese, diziéndole que por çierto él le guardaría de buena voluntad la jura e prometimiento que le avía fecho así commo marido a muger si pudiese, mas aquellos que avían poderío le avían tirado el albedrío qu'él cuydava que avía para le fazer. Enpero, qu'el segundo prometimiento que avía fecho, es a saber, que nunca la entregaría a poder de los romanos qu'él le guardaría e que le rogava que ella considerase e parase mientes cómo era natural de Cartago e fija de Hasdrúbal e muger de dos reys numidianos, e por ende que ordenase de sí cómo non viniese a poder de romanos. Este mensagero traxo el benino a Sinphonisa, e quando ella lo vio, tomó el vaso e dixo estas palabras: «Yo tomo, dixo ella, estos dones de mi esposo, e por çierto non me pesa con ellos pues que el don es tan grande /f.CCCCVI ${ }^{\mathrm{vb}} /$ que mi marido non puede dar mayor a su muger; enpero tú le dirás así al que me lo enbía que mejor me fuera a mí no aver seýdo casada que casar para morir por ello». E non dixo más palabras, e tomó el vaso do estava el benino e beviólo todo sin fazer ningund senblante de miedo. 


\section{REFERENCIAS BIBLIOGRÁFICAS}

Aubrun, Ch.V. (1951), Le chansonier espagnol d'Herberay des Essarts (XVe siècle), edition précédée d'une étude historique, Burdeos, Féret et Fils Éditeurs.

Baquero Escudero, A.L. (1999), «La técnica epistolar en la novela sentimental de la Edad Media», Estudios Románicos 11, pp.7-16.

Belloso, N. (2000), Alfonso Fernández de Madrigal, «El Tostado», Brevyloquio de amor e amiçiçia, Pamplona, Universidad de Navarra.

Borgo, A. (2011), «Lucrezia. Riflessioni sulla storia di un personaggio letterario», Bolletino di Studi Latini 41, pp.43-60.

BuRIDANT, C. (1983), «Translatio medievalis. Théorie et pratique de la traduction médiévale», Travaux de Linguistique et Littérature 21, pp.81-136.

CAppelli, G.M. (2007), El humanismo Italiano: Un capitulo de la cultura europea entre Petrarca y Valla, Madrid, Alianza Editorial (libro traducido al italiano y publicado en Roma, 2010).

CÁtedra, P. (1986), Del Tostado sobre el amor, Barcelona, Stelle dell'Orsa.

CÁtedra, P. (1989), Amor y pedagogía. Estudios de doctrina amorosa y práctica, Salamanca, Universidad.

Colombí-Monguió, R.A. - Higashi, A. (eds.) (2013), Francesco Petrarca, La lira y el laurel: Poesía latina selecta, edición bilingüe. Selección, traducción en verso y notas de Alicia de Colombí-Monguió. Introducción y notas de Alejandro Higashi, Barcelona - México, Anthropos Editorial - UAM-Iztalapapa, División de Ciencias Sociales y Humanidades.

CORTIJO OCAÑA, A. - CORTIJO OCAÑA, A. (1998), «Las cartas de amores: ¿otro género perdido de la literatura hispánica?», DICENDA. Cuadernos de Filología Hispánica 16, pp.63-81.

CORTIJO OCAÑA, A. (2001), La evolución genérica de la ficción sentimental de los siglos XVy XVI. Género literario y contexto social, Londres, Tamesis.

Croce, B. (1953), «Intorno a Lucrezia ella poesía en ella casistica morale», en Aneddoti de varia letteratura, I, Bari, Laterza, pp.400-410 (artículo publicado primero en Critica 35 [1937], pp.146-152).

DÖRRIE, H. (1966), «L’Épitre héroïque dans les Littératures modernes», Revue de littérature comparée 40.1, pp.48-64.

FollaK, J. (2002), Lucretia zwisschen positiver und negativer Anthropologie: Coluccio Salutati's 'Declamatio Lucretie' und die Menschenbilder im exemplum der Lucretia von der Antike bis in die Neuzeit, Dissertation zur Erlangung des akademisches Grades des Doktors der Philosophie an der Universität Konstanz Fachbereich Literaturwissenschaft (10-6-2002) (http://nbn-resolving.de/urn:nbn:de:bsz:352-opus-9144).

Fontanarosa, S. (1999a), «La fortuna di Lucrezia. Ricezione e attualizzazione di un modelo di virtù muliebre.1. Tra Medievo e rinascimento», Aufidus 38, pp.115-147

FontANAROSA, S. (1999b), «Iconografia e produzione letteraria: ricerche, riflessione, da Livio a Girodoux», Aufidus 39, pp.93-121.

Frenzel, E. (1976), Diccionario de argumentos de la literatura universal (versión española de C. Schad de Caneda), Madrid, Gredos.

GARIN, E. (1986), El Renacimiento italiano (trad. esp. de A. Vicens), Barcelona, Ariel.

Gómez Moreno, A. - Kerkhof, M.P.A. (1988), Íñigo López de Mendoza, Marqués de Santillana, Obras completas. Edición, introducción y notas, Barcelona, Planeta. 
Gómez Redondo, F. (2002), Historia de la prosa medieval castellana.III. Los orígenes del Humanismo. El marco cultural de Enrique III y Juan II, Madrid, Cátedra.

GonzÁlez Rolán, T. - SAquero SuÁRez-Somonte, P. (en prensa), «La cartaginesa Sofonisba (c.218-203 a. C.), un ejemplo de patriotismo, fortaleza de ánimo y dignidad personal», ASPARKÍA.

Heerstraten, E. van der, (ed.) (1487), Giovanni Boccaccio, De claris mulieribus, Lovaina.

Hurus, P. (impr.) (1494), Tratado de Johan Boccaccio. De las mujeres ilustres en romance, Zaragoza.

JED, S.H. (1987), «Salutati's Declamatio Lucretie. The Rape of Lucretia and the Birth of Humanism», Genre 20, pp.209-226.

JED, S.H. (1989), Chaste Thinking. The Rape of Lucretia and the Birth of Humanism, Bloomington, IN.

KRISTELLER, P.O. (1963-1997), Iter Italicum: A Finding List of Uncatalogued or Incompletely Manuscripts of the Renaissance in Italian and otherLibraries, 6 vols. +2 apéndices, Londres, Warburg Institute.

LeNOIR, R. (2002), Pétrarque. L'Afrique (1338-1374), Préface de Henri Lamarque. Introduction, traduction et notes de Rebecca Lenoir, Grenoble, Éditions Jérôme Millon.

LidA DE MALKIEL, Mª.R. (1977), «Juan Rodríguez del Padrón. Vida y obras. Influencia. Adiciones», en Estudios sobre la Literatura Española del siglo XV, Madrid, Ediciones José Porrua Turanzas, pp.82-87.

Menestò, E. (1971), Coluccio Salutati. Editi e inediti latini dal Ms. 53 della biblioteca comunale di Todi, Todi, Editorial, pp.34-43 y 67-70.

Menestò, E. (1979), «La 'Declamatio Lucretiae' del Salutati: manoscritti e fonti», Studi Medievali $3^{\text {a }}$ Serie, 20.3, pp.917-924.

Morrás, M. (2010), «Coluccio Salutati en España: La versión romance de las Declamationes Lucretiae», La Corónica. A Journal of Medieval Hispanic Languages, Literatures and Cultures 29.1, pp.209-247.

Moya del BAÑo, F. (1995-1996), «El romance de Tarquino y Lucrecia», Miscelánea Medieval Murciana XIX-XX, pp.233-244.

Moya DEl BAÑo, F. (ed.) (1986), Ovidio, Heroidas, texto revisado y traducido, Madrid, CSIC.

Müller, H. (1874), «Johannes Herrgotts Libellus de virtute colenda. Nebst einigen Briefen und Reden von ihm und an ihn, nach der Greifswalder Handschrift (Mss. Lat. Fol. 15) », Archiv für Litteraturgeschicht 3, pp.169-201; 289-323.

MuÑIz MuÑIz, Ma.N. (2012), «La Declamatio Lucretie di Salutati e la sua traduzione quattrocentesca castigliana», en L'immagine riflessa. Percezione nazionale e trame intertestuali fra Italia e Spagna (da Petrarca a Montale, da Garcilaso a Guillén), Florencia, Franco Cesati Editore, pp.43-70.

Otero Vidal, M. (1996), «¿Si adulterata, cur laudata...?», Scriptura 12, pp.33-49.

PAmpín, M. (2002), «Cartas originales de Juan Rodriguez del Padrón», en C. Alvar - J.M. Lucía Megías (eds.), Diccionario filológico de literatura medieval española: textos y transmisión, Madrid, Castalia.

Riber, L. (1963), San Agustín, La ciudad de Dios. Libros I-II, traducción de Lorenzo Riber, texto revisado por Juan Bastardas, Barcelona, CSIC.

Rossi, V. (ed.) (2008), Francesco Petrarca, Le familiari, Florencia, Casa Editrice Le Lettere. 
Saquero SuÁrez-Somonte, P. - GonzÁlez Rolán, T. (2010), Juan Rodríguez del Padrón, BURSARIO. Edición, introducción y notas, Alcalá de Henares, Centro de Estudios Cervantinos.

Saquero SuÁRez-Somonte, P. (2012), «Las cartas de Troilo a Briseida de Juan Rodríguez del Padrón en las Bienandanzas e fortunas de Lope García de Salazar», Cuadernos de Filología Clásica. Estudios Latinos, 32.1, pp.145-171.

Saquero SuÁrez-Somonte, P. (en prensa), «Ovidio en el Medievo hispánico: un nuevo y completo manuscrito del Bursario y de una de las cartas originales (Madreselva a Mauseol) de Juan Rodríguez del Padrón», Secrets and Discovery in the Middle Ages. 5th International Congress of Medieval Studies, Oporto, 25-29 de junio de 2013.

Schiff, M. (1905, reed. 1970), La Bibliothèque du Marquis de Santillane. Étude historique et bibliogrphique de la collection de libres manuscrits de don Iñigo López de Mendoza,1398-1458, Marquis de Santillana, Conde del Real de Manzanares, humaniste et auteur espagnol célèbre, Amsterdam, Gérard Th. Van Heusden.

Ullman, B. (1963), The Humanism of Coluccio Salutati, Padua, Antenore.

WitT, R. (1983), Hercules at the Crossroads. The Life, and Thought of Coluccio Salutati, University of North Carolina Press.

Wittlin, C. J. (2001), «Tipología de los errores cometidos por traductores medievales», en T. Martínez Romero - R. Recio (eds.), Essays on Medieval Translation in the Iberian Peninsula, Castellón de la Plana, Universitat Jaume I-Creighton University, pp.341-350.

Wittlin, C. J. (sin año), Pero López de Ayala, Las Décadas de Tito Livio, Tomo I. Edición crítica de los libros I al III con introducción y notas, Barcelona, Puvill Libros.

ZACCARIA, V. (ed.) (1970), De mulieribus claris, Milán.

Zintzen, C. - Ecker, U. - Riener, P. (1992), Coluccio Salutati. Index, Tubinga. 